\title{
Research on Evaluation of Equity Financing Efficiency of Listed Companies in Strategic Emerging Industries
}

\author{
Yaxi Huang*, Mu Zhang \\ School of Finance, Guizhou University of Finance and Economics, Guiyang 550025, China
}

Received 11 September 2017

Accepted 3 November 2017

\begin{abstract}
This paper chooses 198 listed companies in strategic emerging industries, using DEA model to study the efficiency of equity financing, and carries on efficiency analysis, investment redundancy and output shortage analysis and industry comparative analysis. The results show that the efficiency of equity financing of listed companies in strategic emerging industries is inefficient. The comprehensive efficiency, pure technical efficiency and scale efficiency are $0.370,0.603$ and 0.563 . From the scale pay, the economic scale of Chuanrungufen should be increased, Zhongguobaoan and other 179 decision-making units should be reduced; Dongxulantian and other 169 decision-making units have different levels of input redundancy and lack of output; equity financing efficiency is unevenly developed between different industries.
\end{abstract}

Keywords: Strategic emerging industries, Financing efficiency, Equity financing efficiency evaluation, Data envelopment analysis (DEA)

\section{Introduction}

Strategic emerging industries refer to breaking new ground in major cutting-edge technologies, representing the new direction for the development of science and technology and industry, and embodying the trend of development of the knowledge-based economy, circular economy and low-carbon economy in the world today. September 8, 2010 Premier Wen Jiabao chaired a meeting of the Standing Committee of the State Council to consider and adopt the "Accelerate the Cultivation and Development of Strategic Emerging Industries Decision" will be energy saving and environmental protection, a new generation of information technology, biomedicine, high-end equipment manufacturing, new energy sources, new materials and new energy vehicles and other seven industries designated as China's key strategic development of new industries. This injected a new

\footnotetext{
* Corresponding author: E-mail: 1308113622@qq.com.
}

force into promoting the upgrading of China's industrial structure and effectively meeting social needs and supply. Strategic emerging industries are guided by Deng Xiaoping theory and the important thought of "Three Represents". They insist on giving full play to the fundamental role of the market and promoting the government-led role, insist on combining scientific and technological innovation with industrialization, and adhering to the overall promotion the four basic principles of combining the development across key areas with each other and insisting on enhancing the long-term competitiveness of the national economy and supporting the current development are committed to providing strong support for the sustainable economic and social development.

The theory of pecking order in corporate financing argues that the best financing order should be endogenous financing first and then exogenous financing. Exogenous financing should first be debt financing, and then equity financing ${ }^{[1]}$. However, the choice of financing methods in Chinese companies is 
the opposite. The financing structure of China's listed companies is mainly based on external financing, and the external financing is up to $80 \%$ of the financing structure. The internal financing is generally less than $20 \%$ of the financing structure, and a few even depend entirely on external financing. In terms of foreign financing, listed companies in China generally prefer equity financing, and debt financing is not considered. Therefore, it is impossible to optimize the company's financing structure by coordinating the proportion of equity financing and debt financing ${ }^{[2]}$. The sustainable development of strategic emerging industries cannot be separated from the choice of financing methods. And the capital-intensive and technology-intensive strategic emerging industries prefer the of equity financing. ${ }^{[3]}$ Equity financing efficiency can effectively measure the degree of perfection of China's capital market and the degree of resource allocation, which is of great significance for national economic growth and sustainable development of strategic emerging industries. $^{[4]}$ Therefore, how to accurately and effectively evaluate the efficiency of equity financing of strategic new industry listed companies has become a major issue in the sustainable development of new strategic industries.

\section{Literature review}

As a way of exogenous financing, equity financing mainly refers to the behavior of listed companies raising funds by issuing shares, including two ways: public offering and private offering. In order to effectively study the efficiency of equity financing of listed companies in strategic new industries, this paper finds that many domestic and foreign scholars have studied equity financing and equity financing efficiency.

The famous American financial expert Modigliani and Miller (1958) ${ }^{[5]}$ in the "American economic review published entitled" the cost of capital, corporate finance and investment theory "of the thesis, the thesis put forward the famous MM theory, they think, in the condition of perfect capital market, because of arbitrage mechanism, the company issued shares regardless of financing or bond financing will not affect the value of the company, namely, capital structure and company value. Sayuri Shirai (2004) ${ }^{[6]}$ based on the theory of financing constraints, constructs a regression model of the three ways of equity financing, bank lending and debt financing, which affect the company's investment decisions. The empirical results show that equity financing has not played a significant role, and thus lack of financing efficiency. Charnes et al (1989) ${ }^{[7]}$ first introduced the DEA method into the evaluation of urban economic growth efficiency, and compared the economic performance level of 28 cities in China in 1983 and 1984. Sueyoshi (1992) ${ }^{[8]}$ expanded the application of DEA in the area of urban efficiency evaluation, and investigated the resource allocation efficiency of 35 cities in China using DEA/AR model.

The domestic scholar Zhengde Xiong, Fangjuan Yang and Jun Wan (2014) ${ }^{[9]}$ using two stage relational network DEA model, with the cost of debt financing, debt financing risk as input indexes, rate of return on assets, total assets turnover, operating income growth rate as output indexes, the debt financing efficiency of China's new energy automotive industry listed companies and the corresponding sub stage efficiency was calculated. Li Jingwen, Wang Yuchun et al (2014) ${ }^{[10]}$ took the 51 strategic emerging industries listed companies in Beijing as samples, selected ten quarterly financial data since 2011, and took total assets, assetliability ratio and total operating costs as input indexes, return on net assets, total asset turnover, total revenue growth as output indexes, using DEA method to measure and analyze financing efficiency. According to the total assets, assets and liabilities ratio as input indexes, return on net assets and Tobin's $\mathrm{Q}$ as the output indexes, Xiaoyan Qiao and Dongjun Mao (2015) ${ }^{[1]}$ used DEA method to compare and analyze the efficiency of equity financing for 2010-2013 years in Jiangsu province 15 listed companies of the new energy, and based on the above results, the influence factors of efficiency are analyzed by the fixed effect model. Qiong Wang, Chengxuan Geng (2016) ${ }^{[12]}$ extended the multi-stage DEA model, taking non-flow accountable and capital public reserve as input indexes and net profit and total operating revenue as output indexes to build a six-stage Super-SBM model Malmquist index model, the static and dynamic evaluation of the financing efficiency of 29 listed companies in strategic emerging industries in Jiangsu Province for 2009-2014. Ruibo Liu and Xuemei Zhang (2009) ${ }^{[13]}$ from the perspective of financing efficiency, 
apply data envelopment analysis (DEA) to the analysis and evaluation of the efficiency of equity financing of Expressway listed companies. The empirical results show that the efficiency of equity financing of our expressway listed companies is relatively low. We should improve the efficiency of equity financing from reforming input scale of equity financing, equity concentration and other input indexes, main business income growth rate and net assets yield index. Lichang Liu and Genfu Feng et al (2004) ${ }^{[14]}$ used the data envelopment analysis method to take the 47 listed companies that initially listed in Shanghai stock market for 1998 as the research object, taking asset-liability ratio and ownership concentration as input indexes, net asset return rate, Tobin's $\mathrm{Q}$ value as the output indexes, a comprehensive evaluation of China's equity financing efficiency. Haokun Yan and Honghong Zhao (2014) ${ }^{[15]}$ take the total assets, asset liability ratio and financial cost as input indexes, main business revenue growth rate and net assets yield ratio as output indexes. They use DEA model to analyze the financing efficiency of 23 listed companies in Inner Mongolia. The results show that the overall financing efficiency of the listed companies in Inner Mongolia is low, and only 5 of the 23 companies are satisfied with the DEA. On the basis of this, the basic idea of optimizing the financing efficiency of the listed companies is put forward. Wen Han, Kaihong Liu (2014) ${ }^{[16]}$ take labor force, operating expenses, paid in capital as input indexes, premium income, payments for the output indexes by DEA model showed that DEA evaluation sample period the insurance business property insurance company operating performance; then, using two step cluster analysis, clustering analysis, clustering results were obtained clear. The empirical results demonstrate the feasibility and applicability of the DEA clustering method in the performance evaluation of the insurance business of property insurance companies. Yueping Dai and Hongmei Zhang (2013) ${ }^{[17]}$ choose the data from 2012 and 2011 of China high tech industry statistical yearbook, and use DEA model to evaluate the efficiency of input-output of 31 provinces in China. The results show that the independent innovation efficiency of all the provinces in the last 5 years is generally low, and the national efficiency of Guizhou Province in the last 5 years has been greatly fluctuated and lack of stability.
In summary, most foreign scholars focus on the research on the enterprise value and its influencing factors, and research on the financing efficiency of enterprises. Domestic scholars have studied the financing efficiency of Chinese enterprises, especially the equity financing efficiency from different angles. However, most of them involve strategic emerging industries and their listed companies or their sample size is too small, but they also do not carry out a detailed analysis of their inputs, outputs and industries. Therefore, this article chooses 198 representative listed companies in China's strategic emerging industries as the research object, taking equity financing net value, ownership concentration, asset-liability ratio as input indexes, return on net assets, growth rate of main business, Tobin's $Q$ value as output indexes, using data envelopment analysis (DEA) study on the efficiency of equity financing, and analysis of the efficiency, input redundancy and output deficiency of industry analysis and comparative analysis of the financing efficiency of the three aspects of strategic emerging industries listed companies analysis. This is of great theoretical and practical significance to improve the equity financing efficiency of listed companies in strategic emerging industries and to improve the strategic emerging industry market.

\section{Introduction of DEA model}

\subsection{Fundamental}

Data Envelopment Analysis (DEA) was proposed by Charnes, Coopor and Rhodes in 1978. The principle of this method is to maintain the input or input of DMU (Decision Making Units) by means of Mathematical programming and statistics identify relatively efficient frontiers of production, project each decision-making unit onto the DEA production frontier and evaluate their relative validity by comparing the extent to which decision-making units deviate from the DEA frontier.

Based on the concept of relative efficiency, DEA method uses convex analysis and linear programming as a method of evaluation. The mathematical programming model is used to calculate and compare the relative efficiency between the decision-making units and evaluate the evaluation objects. It can give full consideration to the optimal input-output plan for the decision-making unit itself, so it can reflect the information and characteristics of the evaluation object 
more ideally. Meanwhile, it has its uniqueness for evaluating multi-input and multi-output of complex systems. It has the following characteristics:

First, it is applicable to the comprehensive evaluation of the effectiveness of multi-output and multi-input. It has an absolute advantage in evaluating the effectiveness of multi-output and multi-inputs.

Second, the DEA method does not integrate the data directly. Therefore, the optimal efficiency index of decision-making unit has nothing to do with the dimension selection of input index and output index. There is no need to dimensionless the data before establishing the model using the DEA method.

Third, no weight hypothesis is required. The decision-making unit input and output of the actual data to obtain the optimal weight, excluding a lot of subjective factors, with strong objectivity.

Fourth, the DEA method assumes that each input is associated with one or more outputs. And there is indeed some connection between the input and output, but do not have to determine the display of this relationship.

\subsection{Construction of the model}

\subsubsection{Integrated efficiency model (CCR model)}

There are $\mathrm{n}$ decision units $\mathrm{DMU}_{j}$, where $j=1,2, \ldots, n$. Any DMU has $\mathrm{m}$ input vectors (input production factors) and s output vectors (output obtained), then

$X_{j}=\left(x_{1 j}, x_{2 j}, x_{3 j} \ldots x_{m j}\right)>0, \quad j=$ $1,2, \ldots, n$

$Y_{j}=\left(y_{1 j}, y_{2 j}, y_{3 j} \ldots y_{s j}\right)>0, j=1,2, \ldots, n$

Where $j=1,2, \ldots, n, \mathrm{X}_{m j}$ denotes that the jth decision unit has $\mathrm{m}$ kinds of inputs, and $Y_{s j}$ denotes the sth input of the jth decision unit. So for the jthDMU $\mathrm{Decision}_{j}$ unit based on the minimum, inefficient, convex hypothesis production set:

$T=\left\{(X, Y) \mid \sum_{j=1}^{n} X_{j} \lambda_{j} \leq \mathrm{X}, \sum_{j=1}^{n} X_{j} \lambda_{j} \geq Y, \lambda_{j} \geq 0, j=1,2, \ldots, n\right.$

The input validity model of the DMU has the following CCRs:

$$
\left\{\begin{array}{c}
\min \theta \\
\sum_{j=1}^{n} X_{j} \lambda_{j}+S^{-}=\theta X_{0} \\
\sum_{j=1}^{n} Y_{j} \lambda_{j}-S^{+}=Y_{0} \\
\lambda_{j} \geq 0, \mathrm{j}=1,2 \ldots \mathrm{n} \\
S^{+} \geq 0, S^{-} \geq 0
\end{array}\right.
$$

The CCR model is "comprehensively effective" in terms of the effective and technologically efficient DMU. Assuming that the optimal solution is $\theta$, $\lambda, S^{+}, S^{-}$, the effective judgments and economic explanations are as follows:

(1) If $\theta=1, S^{+}=0, S^{-}=0$, then the decision unit $\mathrm{DMU}_{j}$ is said to be valid for the DEA under the CCR model, indicating that the decision unit is comprehensive and effective, that is, both the scale efficiency and the technical efficiency Best, there is no "excess" investment and "deficit" output;

(2) If $\theta=1, S^{+} \neq 0, S^{-} \neq 0$, the decision unit $\mathrm{DMU}_{j}$ is said to be weakly valid for the DEA in the CCR model. Although there is no need for isometric compression in terms of input, there are some aspects of "excess" Input or "deficit" output;

(3) If $\theta<1$, then the decision unit $\mathrm{DMU}_{j}$ is said to be valid for non-DEA under the CCR model, indicating that the input can be fully compressed by $\theta^{[18]}$.

\subsubsection{Technical efficiency model (CCGSS model)}

There are $\mathrm{n}$ decision unitsDMU $\mathrm{DM}_{j}$, where $j=1,2, \ldots, n$, And $X_{j}=\left(x_{1 j}, x_{2 j}, x_{3 j} \ldots x_{m j}\right)>0 \quad, \quad Y_{j}=$ $\left(y_{1 j}, y_{2 j}, y_{3 j} \ldots y_{s j}\right)>0$, the CCGSS model is

$$
\left\{\begin{array}{c}
\text { s.t. } \sum_{j=1}^{n} X_{j} \lambda_{j}+S^{-}=\theta X_{0} \\
\sum_{j=1}^{n} Y_{j} \lambda_{J}-S^{+}=Y_{0} \\
\sum_{j=1}^{n} \lambda_{j}=1 \\
\lambda_{j} \geq 0, j=1,2, \ldots, n \\
S^{+} \geq 0, S^{-} \geq 0
\end{array}\right.
$$

The optimal value can be obtained by this model. When $\sum_{j=1}^{n} \lambda_{j}<1$ is the scale returns increasing, 
$\sum_{j=1}^{n} \lambda_{j}=1$ is the scale returns constant; $\sum_{j=1}^{n} \lambda_{j}>1$ is the decreasing returns to scale. Suppose the optimal solution is $\theta, \lambda, S^{+}, S^{-}$, the effective judgments and economic explanations are as follows:

(1)If $\theta<1$ or $S^{+} \neq 0, S^{-} \neq 0, \mathrm{DMU}_{j}$ is non-DEA valid (CCGSS);

(2)If $\mathrm{I}=1, S^{+}=0, S^{-}=0$, thenDMU $\mathrm{H}_{j}$ is DEA valid

\section{(CCGSS).}

When (2) is satisfied, it indicates that $\mathrm{DMU}_{j}$ is purely technical, otherwise non-technical. When $S^{-} \neq 0$, it indicates that there is excess investment; when $S^{+} \neq 0$, it indicates that there is a loss output. When $0<\theta<1$, it indicates that the DMU is improperly input and can be compressed in equal ratio, which is non-technical and effective.

To sum up, the CCR model is used to evaluate whether the decision-making unit is both efficient and technically effective. However, the CCGSS model is only used to evaluate whether the technical efficiency is the best. Combining the two can make the combination of technical efficiency and economies of scale Analysis [19].

\subsection{General steps}

\subsubsection{Determine the evaluation objectives}

Evaluation is the most basic function of DEA model, which is the basis of our correct application of DEA model. Only by determining the purpose of evaluation, can we find the right direction, select the appropriate model and collect the appropriate data to substantiate the problems in production and life. This requires that we be able to accurately translate the information in economic activity into the information required by the DEA model or to correspond one-on-one with the relevant concepts of DEA.

\subsubsection{Select the decision unit $D M U$}

Since DEA evaluates the relative validity of DMUs of the same type, the following two points need to be followed in the selection of DMUs: First, DMUs must be of the same type, DMUs of the same nature or DMUs with the same time interval; Then, the number of DMU should be selected as the input and output data of the sum of 2 times is appropriate.

\subsubsection{Establish input and output index system}

The establishment of the input and output index system needs to pay attention to the following points: First of all, it is necessary to reflect the purpose of evaluation truthfully and comprehensively. Secondly, attention should be paid to the relationship between input indicators and output indicators. At the same time, we should try to avoid the multiple linear relationship between input and output indicators; Finally, to ensure the diversity and availability of input and output indicators.

\subsubsection{Select the DEA model}

The choice of DEA model to follow the following two requirements: first, pay attention to the actual production and life background; the second is to choose the DEA model for evaluation purposes. In addition, different models can be applied for multi-angle analysis in order to arrive at a more comprehensive evaluation.

\subsubsection{Evaluation and analysis of DEA results}

This is the most critical step in the application of DEA model. By collecting data and calculating models, we get the result of DEA model. Based on this result, we analyze the real economic problems, and provide an accurate direction for policymakers to formulate effective policies and solve practical problems.

\subsubsection{Adjust the input and output index system}

When the result of DEA evaluation and analysis is unsatisfactory, we should adjust the input and output index system appropriately and reconsider it without violating the purpose of evaluation. By using a variety of DEA models to analyze different angles, the different results are compared and the important factors that affect the decision making unit are observed.

\subsubsection{Draw a comprehensive analysis and evaluate the conclusion}

By calculating the DEA model, we can get the following information: the DEA validity of each DMU, the relationship between the relative efficiency of DMU and the input and output indexes, the relative effective production frontier and the projection of DMU on the 
effective production frontier. To make a comprehensive analysis and evaluation of these results, we can formulate a scientific and reasonable policy ${ }^{[20]}$.

\section{Empirical analysis}

\subsection{Determination of evaluation index}

\subsubsection{Input indexes}

(1) Equity financing net value

Since this paper mainly investigates the efficiency of equity financing, after we choose the total amount of equity financing acquired by the company after IPO, deducting the weighted financing cost, we get the net equity financing of the company. In order to ensure the validity of the model, it is transformed into a dimensionless the amount.

(2) Ownership concentration

The degree of ownership concentration affects the company's financing efficiency through its influence on the company's daily operation, so it is used as an input index to investigate the efficiency of financing. The index mainly uses the largest shareholders to share the total number of shares issued.

(3) Asset liability ratio

The target is to reflect the impact of the company's financial structure on equity financing. The calculation method is to divide the total liabilities of the listed company by the total assets. This index mainly investigates the relationship between the tax credit effect and the financing cost of the creditor's rights.

\subsubsection{Output indexes}

(1)Return on equity

This index reflects the profitability of shareholder investment in production and operation, which is the ratio of the company's net profit to the average net asset over a period of time. This paper introduces this index in the empirical evidence, intended to use this index to measure whether the profitability of the company after the equity financing has been enhanced.

(2) Main business revenue growth rate

This index reflects the company's growth ability. It can be calculated from the increase of income from main business over the previous year.

\section{(3) Tobin Q}

Tobin's Q reflects the allocation efficiency of equity financing, equal to the total market price divided by the replacement value. Since the replacement value of the company is assessed through acquisition, the replacement value is replaced by the net asset value of the company, which is the ratio of total turnover to total turnover over the years since the equity financing.

Table 4-1 Input and Output Indexes

\begin{tabular}{|c|c|}
\hline Input indexes & Output indexes \\
\hline Equity financing net value & Return on equity \\
\hline Ownership concentration & $\begin{array}{c}\text { Main business revenue } \\
\text { growth rate }\end{array}$ \\
\hline Asset liability ratio & Tobin Q \\
\hline
\end{tabular}

\subsection{Sample Selection and Data Sources}

This paper chooses 198 companies with certain representativeness and comparability as the research object after excluding the changes of the financial statements before and after the listing of the company, the negative output indicators and the financial indicators such as the secondary issuance. According to DEA's experience, it is only meaningful to analyze the sample size at least twice to three times more than the total number of input variables and output variables. The total number of input and output variables in this paper is 6 , which meets the requirements. The data in this paper are all from the database of Tai' an (CSMAR) series research database. The sample table of the company in this paper is shown in table 1 of appendix. Strategic new industries are divided into seven industries: energy saving, environmental protection, a new generation of information technology, biomedicine, high-end equipment manufacturing, new energy, new materials and new energy vehicles. Among the research objects in this sample, there are 29 energy saving and environmental protection industries, a total of 25 new generation of information technology industry, 34 biomedical industry, 30 high-end equipment manufacturing industry, 27 new energy industry, 25 new material industry, 28 new energy vehicle industry. The proportion of sample companies selected by each industry is shown in Fig.4-1. 


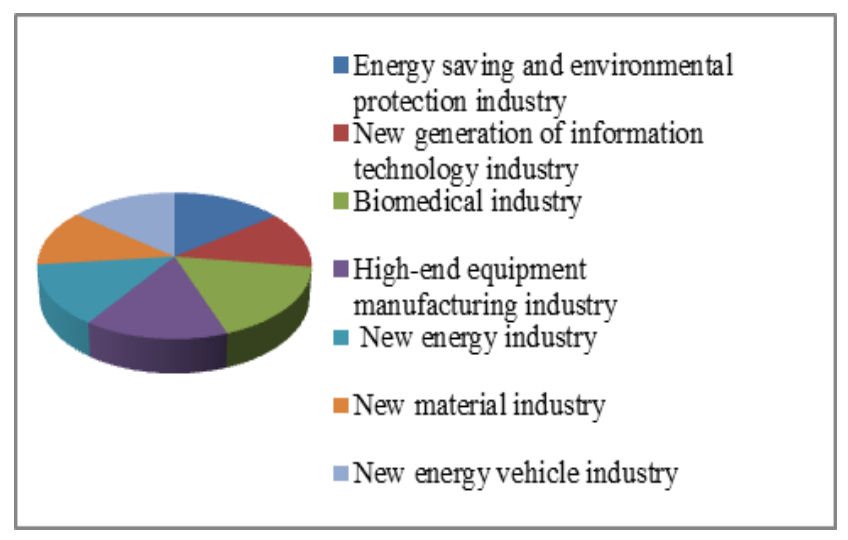

Fig.4-1 Distribution of Selected Samples by Industry

In this paper, the database of Tai an (CSMAR) series research database are selected as input indexes and output indexes of each sample company in 2016, and the original data of each sample company are shown in table 2 of appendix.

\subsection{Evaluation results of equity financing efficiency}

This article intends to use DEAP Version 2.1 software to research the issue of equity financing efficiency of strategic new listed companies. The original data of input and output indexes in table 2 of appendix are substituted into the model software for calculation, and the shares of the strategic new industry listed companies financing evaluation results and the overall situation (see table 4-2), the evaluation results of equity financing of listed companies in strategic emerging industries are shown in table 3 of appendix.

\subsection{Analysis of the evaluation results of equity financing efficiency}

\subsubsection{Efficiency analysis}

(1) Comprehensive efficiency

The comprehensive efficiency is a comprehensive measure and evaluation of various aspects of the ability of resource allocation and resource utilization of decision-making units. As seen from table 3 of appendix and table 4-2, from the comprehensive efficiency of DEA measurement, in 2016, the comprehensive efficiency of 18 decision-making units such as Shenzhennengyuan, Yichengxinneng, Shangqijituan Zhenhuazhonggong, Xugongjixie, Liugong, Haimaqiche, yinxinnengyuan, Hebeixuangong, Haigetongxin and Wandongyiliao and so on reached 1, indicating that the inputs and outputs of the above decision-making units are comprehensive and effective that is both technically effective and scale effective. The proportion of comprehensive and effective decision-making units is $9.09 \%$. However, the average comprehensive efficiency of the 198 publicly listed companies in strategic emerging industries is 0.370 , indicating that the input and output of listed companies in strategic emerging industries are not comprehensively and effectively implemented. Among them, Zhongguobaoan, Dongxulantian, Desaidianchi, Tefaxinxi, Haiwangshenwu, Fengyuanyaoye, Xujidianchi, Yingtejituan, Zhongyuanhuanbao and other 180 decision-making units still has some space for improvement and improvement.

(2) Pure technical efficiency

Pure technical efficiency is the production efficiency of decision-making unit due to factors such as management and technology. It can be seen from table 3 of appendix and table 4-2,from the purely technical efficiency of DEA measurement, in 2016, the pure technical efficiency of 29 decision-making units such as Shenzhenneneyuan, Yamadun, Yinengxincheng, Yaxingkeche, Hongduhankong, Zhenhuazhonggong, Xugongjixie, Liugong, Haimaqiche, Yinxing Energy, Ankaikeche, HebeixuanongHager and so on reached 1, indicating that at the current technical level, the abovementioned decision-making unit invested in the use of resources is efficient. The proportion of purely technical and effective decision making units is $14.65 \%$. However, the average pure technical efficiency of the

Table 4-2 The overall efficiency of equity financing efficiency in strategic emerging industries

\begin{tabular}{|c|c|c|c|}
\hline & Comprehensive efficiency & Pure technical efficiency & Scale efficiency \\
\hline DEA effective & $18(9.09 \%)$ & $29(14.65 \%)$ & $18(9.09 \%)$ \\
\hline Non DEA effective & $180(90.91 \%)$ & $169(85.35 \%)$ & $180(90.91 \%)$ \\
\hline Mean & 0.370 & 0.603 & 0.563 \\
\hline
\end{tabular}


198 publicly listed companies in the strategic emerging industries is 0.603 , which is not entirely technically effective. Among them, the management and technical level of 169 decision-making units such as Zhongguobaoan, Dongxulantian, Desaidianchi, Tefaxinxi, Haiwangshenwu, Fengyuanyaoye, Xujidianchi, Yingtejituan, Zhongyuanhuanbao, Wanxiangqianchao, Chinaguangheji, Huanruishiji, Kaidishentai, Xinxianghuaxian and Zhongkesanhuan should be improved.

(3) Scale efficiency

Scale efficiency is the production efficiency that is affected by the size of the decision unit. it can be seen from table 3 of appendix and table 4-2, from the scale efficiency of DEA measurement, in 2016, , The scale efficiency of 18 decision making units such as Shenzhennengyuan, Yinengxincheng, Zhenhuazhonggong, Xugongjixie, Liugong, Haimaqiche, Yinxingnengyuan, Hebeiuangong, Haigetongxin, Daomingguangxue and Wandongyiliao reached 1 , indicating that these decision-making units are effective in scale. The proportion of effective decision-making units is $9.09 \%$. However, the average of the scale efficiency of the 198 listed companies that represent the strategic emerging industries is 0.563 , indicating that the overall performance of strategic emerging industries listed companies is not achieved. Among them, the scale efficiency of 180 decisionmaking units such as Zhongguobaoan, Dongxulantian, Desaidianchi, Tefaxinxi, Haiwangshenwu, Fengyuanyaoye, Xujidianqi, Yingtejituan, Zhongyuanhuanbao, Wanxiangqianchao, Fenghuagaoke, Huitianredian and Zhongtaiqiche still has some room for improvement and improvement.

(4) Returns to scale

From the returns to scale of view, Chuanrungufen shows the increasing returns to scale in production within the boundaries, that should be appropriate to increase the size of its economy, the scale and the input and output matching; Zhongguobaoan, Dongxulantian, Desaidianchi Tefaxinxi, Haiwangshenwu, Fengyuanyaoye, Xujidianchi, Yingtejituan, Zhongyuanhuanbao, Wanxiangqianchao, Fenghuagaoke, Zhongguangheji, Huanruishiji, Kaidishentai, Xinxianghuaxian, Zhongkesanhuan, Zhongtaiqiche, Huagongkeji, Jingxinyaoye, Xinhaiyi, Jinzhikeji, Leibaogaoje, Wohuayiyao, Sanweitongxin and other
179 decision-making unit in the production boundary performance of scale returns diminishing, indicating that its economic size should be appropriately reduced to make the scale and investment matching; the remaining 18 decision-making units in the production boundary performance for the same scale returns, then the economy should remain the same size.

\subsubsection{Analysis of insufficient input redundant output}

DEAP Version 2.1 software gives the DEA evaluation value of equity financing efficiency of listed companies in strategic emerging industries, and also gives the values of slack variables of inputs and outputs of each decision unit, that is, inputting redundant values and outputs Insufficient value, the results see table 4 of appendix.

Table 4 shows that Zhongguobaoan, Dongxulantian, Desaidianchi, Tefaxinxi, Haiwangshenwu, Fengyuanyaoye, Xujidianchi, Yingtejituan,Zhongyuanhuanbao, Wanxiangqianchao, Fenghuagaoke Huitianredian, Yingluohua, Zhongguangheji, Huanruishiji, Kaidishentai, Xinxianghuaxian, Zhongkesanhuan, Zhongtaiqiche, Huagongkeji, Jingxinyaoye and other 169 decisionmaking unit there are varying degrees of input redundancy and output deficiencies. In the case of Shenwuhuanbao, there were 0.092 million yuan of net investment in equity financing. There was $1.447 \%$ investment redundancy in the ownership concentration and 4.079 in the asset-liability ratio; net assets yield was 91340.018 output deficiency, there are 29.955 output deficits in the main business yield, 0.342 output deficit in Tobin Q. Only after eliminating the above input redundancy and insufficient output can Shenwuhuanbao Company reach purely technical and effective. The remaining 168 decision-making unit input redundant output analysis, and so on.

\subsubsection{Industry comparative analysis}

September 8, 2010 Premier Wen Jiabao chaired a meeting of the Standing Committee of the State Council to consider and adopt the "Accelerate the Cultivation and Development of Strategic Emerging Industries Decision" will be energy saving and environmental protection, a new generation of 
information technology, biomedicine, high-end equipment manufacturing, new energy sources, new materials and new energy vehicles and other seven industries designated as China's key strategic development of new industries. Among them, the energy-saving and environmental protection industries include 29 companies such as Dongxulantian, Zhongyuanhuanbao, Kaidishentai, Huitianxincai, Xianhehuanbao, Shenwuhuanbao, Zhongdianhuanbao, Tianhaohianjing, Zhongcaijieneng and so on; the new generation of information technology industry include 25 companies such as Tefaxinxi, Huanruishiji, Xinhaiyi, Sanweitongxin, Beiweikeji, Guangxunkeji, Shensunda $\mathrm{A}$ and so on. The biopharmaceutical industry includes 34 companies such as Zhongguobaoan, Haiwangshengwu, Fengyuanyaoye, Jingxinoyey, Wohuayiyao and so on. The high-end equipment manufacturing industries include 30 companies such as Xujidianqi, Huagongkeji, Hezhongsizhuang, Siweituxin, Teruide, Zhongguoweixin and so on. The new energy industries include 27 companies such as Shenzhennengyuan, Huitianredian, Yingluohua, Jinzhikeji, Tuorixinneng, Yamadun and so on. The new materials industry include25 companies such as Desaidianchi, Fenghuagaoke, Zhongguangheji, Xinxianghuaxian, Zhongkesanhuan, Xinyegufen, Zhonggangtianhuan and so on. The new energy automotive industries include 28 companies such as Wanxiangqianchao, Zhongtaiqiche, Yinlungufen, Yataigufen and so on.

Based on the data in table 4-3, we can calculate the DEA average of the financing efficiency of the seven major industries such as energy saving and environmental protection, new generation of information technology, biomedicine, high-end equipment manufacturing, new energy, new materials and new energy vehicles. The results, as shown in figures 4-2, 4-3 and 4-4, show that the equity financing efficiency of listed companies in china's strategic emerging industries has an unbalanced development between industries. Among them, the average value of comprehensive efficiency from high to low is the highend equipment manufacturing industry, new energy industry, energy saving and environmental protection industry, new energy automotive industry, a new generation of information technology industry, bio pharmaceutical industry, new materials industry; pure technical average value from high to low is the energy

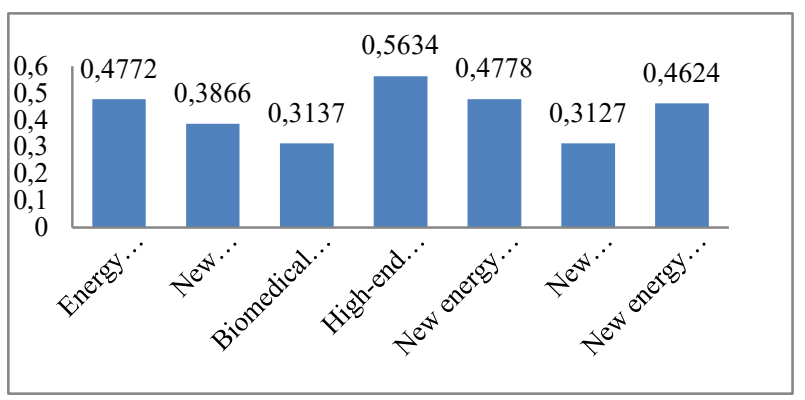

Fig.4-2 The average of the comprehensive efficiency of each industry

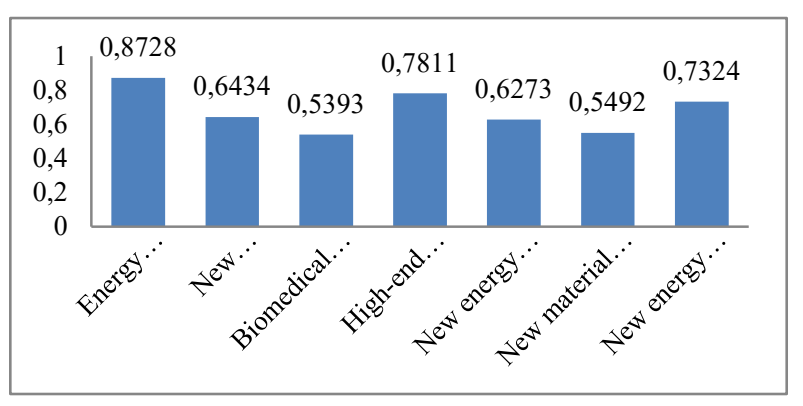

Fig.4-3 The average of pure technical efficiency of each industry

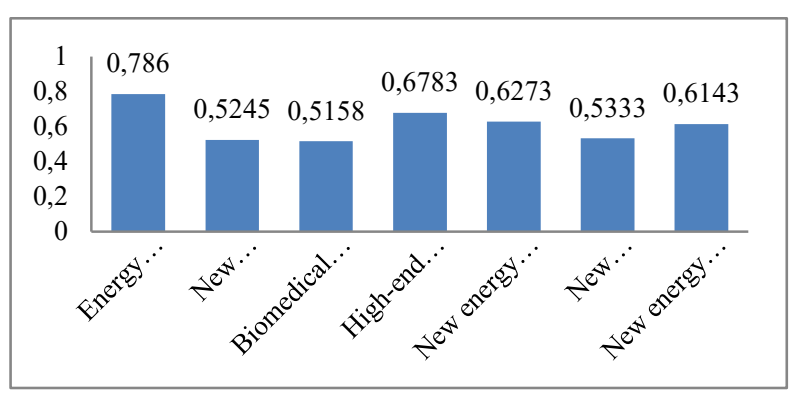

Fig.4-4 The average of scale efficiency of each industry

saving and environmental protection industry, high-end equipment manufacturing industry, the new energy automotive industry, a new generation of information technology industry, new energy industry, new material industry, bio pharmaceutical industry; the average scale efficiency from high to low is the energy saving and environmental protection industry, high-end equipment manufacturing industry, new energy industry, new energy automotive industry, new material industry, a new generation of information technology industry, bio pharmaceutical industry. 


\section{Conclusions}

This paper selects a representative 198 listed companies from the strategic emerging industries as the research object, starting from the efficiency of equity financing based on capital input and output efficiency, with the previous definition of the financing efficiency as the theoretical basis established the evaluation index system of equity financing efficiency, and used DEA$\mathrm{BCC}$ model to evaluate the equity financing efficiency of listed companies in strategic emerging industries, thus draw the following conclusions:

First, the average comprehensive efficiency of listed companies in strategic emerging industries is 0.370 , indicating that the input and output of listed companies in strategic emerging industries are not comprehensively and effectively implemented. Among them, Shenzhennengyuan, Yichengcinneng, Zhenhuazhonggong, Xugongjixie, Liugong, Haimaqiche, Yinxingnengyuan, Hebeixuanong, Haigetongxin, Daomingguangxue, Metainuo, Nandudianyuan, Wandongyiliao and other 18 decisionmaking unit to achieve comprehensive and effective; Zhongguobaoan, Dongxulantian, Desaidianchi, Tefaxinxi, Haiwangshenwu, Fengyuanyaoye, Xujidianqi, Yingtejituan, Zhongyuanhuanbao and other 180 decision-making units have not been comprehensively and effectively implemented.

Second, the average net technical efficiency of listed companies in strategic emerging industries is 0.603 , which is not entirely purely technical and effective. Among them, 29 decision-making units such as Shenzhennengyuan, Yamadun, Yichengxinneng, Yaxingkeche, Hongduhankong, Zhenhuazhonggong, Xugongjixie, Liugong, Haimaqiche, Yinxingnengyuan, Ankaikeche and Haigetongxin reached the purely technical and effective level. 169 decision-making units such as Zhongguobaoan, Dongxulantian, Desaidianchi, Tefaxinxi, Haiwangshenwu, Fengyuanyaoye, Yingtejituan, Zhongyuanhuanbao Wanxiangqianchao, Fenghuagaoke, Huitianredian, Yingluohua, Huanruishiji, Kaidishentai, Xinxianghuaxian and Zhongkesanhuan did not reach pure Effective technology.

Thirdly, the average size efficiency of listed companies in strategic emerging industries is 0.563 , indicating that the listed companies in strategic emerging industries are not achieving the overall scale effective. Among them, Shenzhennengyuan, Yichengxinneng, Zhenhuazhonggong, Xugongjixie, Liugong, Haimaqiche, Yinxingnengyuan, Hebeixuanong, Haigetongxin, Daomingguangxue, Metainuo, Nandudianyuan, Wandongyiliao and other 18 decision-making unit to achieve the scale of effective. 180 decision-making units such as Zhongguobaoan, Dongxulantian, Desaidianchi, Tefaxinxi, Haiwangshenwu, Fengyuanyaoye, Xujidianqi, Yingtejituan, Zongyuanhuanbao, Wangxiangqianchao, Fenghuagaoke, Huitianredian, Yingluohua, Huanruishiji, Kaidishentai, Xinxianghuaxian, Zhongkesanhuan and Zhongtaiqiche have not achieved the scale effective.

Fourth, From the returns to scale of view, Chuanrungufen's economies of scale should be increased; Zhongguobaoan, Dongxulantian, Desaidianchi, Haiwangshengwu, Fengyuanyaoye, Xujidianchi, Yingtejituan, Zhongyuanhuabao, Wanxiangqianchao, Fenghuagaoke, Huitianredian, , Huanruishiji, Kadishentai, Xinxianghuaxian, Zongtaiqiche, Huagongkeji, Jingxinyaoye, Xinhaiyi and other 179 decision making units should be reduced; the remaining 18 decision making units economic scale should remain unchanged.

Fifth, Zhongguobaoan, Dongxulantian, Desaidianchi, Tefaxinxi, Haiwangshenwu, Fengyuanyaoye, Xujidianqi, Yingtejituan, Zhongyuanhuanbao, Wanxiangqianchao, Fenghuagaoke, Huitianredian, Yingluohua, Huanruishiji, Kaidishentai, Xinxianghuaxian, Zhongkesanhuan, Zhongtaiqiche, Jingxinyaoye, Xinhaiyi and other 169 decision-making units have varying degrees of input redundancy and output deficiencies.

Sixthly, the equity financing efficiency of the listed companies in the strategic emerging industries has the unbalanced development among industries. Among them, the average value of comprehensive efficiency from high to low is the high-end equipment manufacturing industry, new energy industry, energy saving and environmental protection industry, new energy automotive industry, a new generation of information technology industry, bio pharmaceutical industry, new materials industry; pure technical average value from high to low is the energy saving and environmental protection industry, high-end equipment 
manufacturing industry, the new energy automotive industry, a new generation of information technology industry, new energy industry, new material industry, bio pharmaceutical industry; the average scale efficiency from high to low is the energy saving and environmental protection industry, high-end equipment manufacturing industry, new energy industry, new energy automotive industry, new material industry, a new generation of information technology industry, bio pharmaceutical industry. ${ }^{[21]}$

\section{References}

[1] S C Myers, N S Majluf. Corporate Financing and Investment Decisions. When Firms Have Information. That Investors Do Not Have [A]. The Journal of Financial Economies, 1984. (13):187-221.

[2] Zhangsheng Liu. Research on different financing methods and their advantages, [A]. New accounting.2010, (4): 28-32.

[3] Haibo Li. How finance can support the development of strategic emerging industries [N]. People's Daily, 201103-31 (007).

[4] Chen Miao, Wang Liguo. Research on equity financing efficiency of strategic emerging industries based on DEA model [J]. Business, 2015, (16): 202-203.

[5] Franco Modigliani and Merton H Miller. The Cost of Capital Corporate Finance and the Theory of Investment. The American Economic Review [J] .1958(6): 261-297.

[6] Sayuri Shirai. Testing the Three Roles of Equity Markets in Developing Countries: The Case of China. World Development [J]. 2004, (9): 1467-1486.

[7] Charnes A, Cooper W, Shanling Li. Using data envelopment analysis to evaluate efficiency in the economic performance of Chinese cities [J].SocioEconomic Planning Sciences, 1989,23(6): 325-344.

[8] Toshiyuki Sueyoshi. Measuring the industrial performance of Chinese cities by data envelopment analysis [J]. Socio-Economic Planning Sciences, 1992, 26(2): $75-88$.

[9] Zhengde Xiong, Fangjuan Yang, Jun Wan. Debt Financing Efficiency of Listed Companies Based on Two-Stage DEA Model - A Case Study of a Strategic Emerging Industry New Energy Vehicle $[\mathrm{J}]$. Finance and Economics Theory and Practice, 2014, 35 (05): 51-56.

[10] Jingwen Li, Yuchun Wang, Zhengdong Yang. Study on Financing Efficiency of Listed Companies in Strategic Emerging Industries: A Case Study of Beijing [J] .Journal of Economics and Management, 2014, (06): 7482.
[11] Xiaoyan Qiao, Dongjun Mao. Emerging industries equity financing and debt financing support efficiency analysis - Jiangsu Province, the new energy listed companies as an example [J] .Academic Monthly, 2015, (24): 77-80.

[12] Qiong Wang, Xuancheng Geng. Jiangsu province strategic emerging industry financing efficiency of listed company -- Based on the panel data of 2009-2014 [J] East China economic management, 2016, 30 (07): 14-20.

[13] Ruibo Liu, Xuemei Zhang. Analysis of Equity Financing Efficiency of Expressway Listed Companies Based on DEA [J] .Business Research, 2009, (12): 102-105.

[14] Lichang Liu, Genfu Feng, Zhang Daohong, Mao Hongxia. Evaluation of Equity Financing Efficiency of Listed Companies Based on DEA [J]. Systems Engineering, 2004, (01): 55-59.

[15] Haokun Yan. Research on financing efficiency of listed companies in Inner Mongolia [A].Chinese Association for disaster prevention risk based on the method of DEA analysis of Specialized Committee. Information technology risk analysis and crisis response in the China Association for disaster prevention risk analysis of the Specialized Committee sixth annual meeting of China Association for disaster prevention [C]. Risk analysis of Specialized Committee.2014:4.

[16] Han Wen. Research on Insurance Business Performance Evaluation of Property Insurance Companies Based on DEA Clustering [A] .China Disaster Defense Association Risk Analysis Committee .Risk Analysis and Information Technology in Crisis Response - Risk Analysis of China Disaster Defense Association Professional Committee of the Sixth Annual Conference Proceedings [C]. China Disaster Defense Association Risk Analysis Committee, 2014: 5.

[17] Yueping Dai. DEA-based evaluation of China's hightech industry independent innovation efficiency [A].Risk analysis council of China association for disaster prevention, 2013: 6 .

[18] Xiaoying Peng, Qinghua Zhang. Evaluation of equity financing efficiency of coal listed companies based on DEA model [J] .China Mines, 2008, 17 (12): 26-29.

[19] Lichang Liu, Genfu Feng, Daohong Zhang, Hongxia Mao. Based on DEA listed companies equity financing efficiency evaluation [A].Systems Engineering, 2004, 22 (1): 55-59.

[20] Chen Sheng, Juan Pang. Overview of data envelopment analysis (DEA) method [C].Science and Technology Economics, 2016, (20): 5-10.

[21] Mu Zhang, Da-zhi Huang, Hai Zhu. Evaluation of Urban Economic Efficiency in China Considering Environmental Factors [J] .Mathematics and Practice, 2016, 46 (07): 71-80. 


\section{Appendices}

Table 1: 198 listed companies of strategic emerging industries

\begin{tabular}{|c|c|c|c|}
\hline Enterprise name & Stock code & Enterprise name & Stock code \\
\hline Zhongguobaoan & 000009 & Shenzhennengyuan & 000027 \\
\hline Dongxuliantian & 000040 & Desaidianchi & 000049 \\
\hline Tefaxinxi & 000070 & Haiwangshenwu & 000078 \\
\hline Fenyuanyaoye & 000153 & Xujidianqi & 000400 \\
\hline Yingtejituan & 000411 & Zhongyuanhuanbao & 000544 \\
\hline Wanxiangqianchao & 000559 & Fenhuagongke & 000636 \\
\hline Huitianredian & 000692 & Yingluohua & 000795 \\
\hline Zhonguangheji & 000881 & Huanruishiji & 000892 \\
\hline Kaidishentai & 000939 & Xinxianghuanxian & 000949 \\
\hline Zhongkesanhuan & 000970 & Zhongtaiqiche & 000980 \\
\hline Huagongkeji & 000988 & Jingxinyaoye & 002020 \\
\hline Xinhaiyi & 002089 & Jinzhikeji & 002090 \\
\hline Laibaogaoke & 002106 & Wohuayiyao & 002107 \\
\hline Sanweitongxin & 002115 & Yinlungufen & 002126 \\
\hline Tuobangufen & 002139 & Beiweikeji & 002148 \\
\hline Laiyinshenwu & 002166 & Tuorixinneng & 002218 \\
\hline Guanxunkeji & 002281 & Yataigufen & 002284 \\
\hline Gelinmei & 002340 & Hezhongsizhuang & 002383 \\
\hline Siweituxin & 002405 & Duofuduo & 002407 \\
\hline Kanshenggufen & 002418 & Shuanghuanchuangdong & 002472 \\
\hline Rongjiruanjian & 002474 & Jiangfencicai & 002600 \\
\hline Yamadun & 002623 & Teruide & 300001 \\
\hline Yiweilineng & 300014 & Huitianxincai & 300041 \\
\hline Shuzizhengtong & 300075 & Yichengxinneng & 300080 \\
\hline Dongfangrishen & 300118 & Xianhehuanbao & 300137 \\
\hline Shenwuhuanbao & 300156 & Zhengdongzhiyao & 300158 \\
\hline Zhongdianhuanbao & 300172 & Chulingxixin & 300250 \\
\hline Tianhaohuanjing & 300332 & Kanxinxincai & 600076 \\
\hline Shangqijituan & 600104 & Dongkuigufen & 600114 \\
\hline Zhongguoweixing & 600118 & Mingjiangshuidian & 600131 \\
\hline
\end{tabular}




\begin{tabular}{|c|c|c|c|}
\hline Futianqiche & 600166 & Yaxingkeche & 600213 \\
\hline Hongduhangkong & 600316 & Zhneghuazhonggong & 600320 \\
\hline Hangtiandongli & 600343 & Kunyaojituan & 600422 \\
\hline Hengtongguangdian & 600487 & Guihanggufen & 600523 \\
\hline Yijingguangdian & 600537 & Guanguyuan & 600771 \\
\hline ShensangdaA & 000032 & Xugongjixie & 000425 \\
\hline Liugong & 000528 & Haimaqiche & 000572 \\
\hline Qidiguhan & 000590 & Shantuigufen & 000680 \\
\hline Xinyegufen & 000751 & Xinhuazhiyao & 000756 \\
\hline Zhonghanfeiji & 000768 & Bohaihuosai & 600960 \\
\hline Qinchuangjichuang & 000837 & Yinxingnengyuan & 000862 \\
\hline Ankaiqiche & 000868 & Faershen & 000890 \\
\hline Yunneidongli & 000903 & Shandahuate & 000915 \\
\hline Hebeixuangong & 000923 & Zhongguozhongqi & 000951 \\
\hline Fousukeji & 000973 & Jiuzhitang & 000989 \\
\hline Shirongzhaoye & 002016 & Zhouyankeji & 002046 \\
\hline Hengdiandongci & 002056 & Zhonggangtianyuan & 002057 \\
\hline Suzhougude & 002079 & Longjigufen & 601012 \\
\hline Zhongcaijieneng & 603126 & Woerhecai & 002130 \\
\hline Yunhaijinshu & 002182 & Zhengtongdianzi & 002197 \\
\hline Feimaguoji & 002210 & Aotexun & 002227 \\
\hline Aoweitongxin & 002231 & Dahuagufen & 002236 \\
\hline Chuanrungufen & 002272 & Zhongdianxinlong & 002298 \\
\hline Dongfangyuanlin & 002310 & Gellinmei & 002340 \\
\hline Longjijixie & 002363 & Dongshanjingmi & 002384 \\
\hline Neimengyiji & 600967 & Shenglutongxin & 002446 \\
\hline Haigetongxin & 002465 & Fuchunhuanbao & 002479 \\
\hline Keshida & 002518 & Tianshunfengneng & 002531 \\
\hline Yataikeji & 002540 & Yishengyaoye & 002566 \\
\hline Qinxinghuanjing & 002573 & Shenyanggufen & 002580 \\
\hline Daomingguangxue & 002632 & Maoshuodianyuan & 002660 \\
\hline Jingweigufen & 002662 & Teyiyaoye & 002728 \\
\hline Ankeshenwu & 300009 & Jiqiren & 300024 \\
\hline Meitainuo & 300038 & Hekanxinneng & 300048 \\
\hline
\end{tabular}




\begin{tabular}{|c|c|c|c|}
\hline Yujingangshi & 300064 & Nandudianyuan & 300068 \\
\hline Danshenkeji & 300073 & Shengyunhuanbao & 300090 \\
\hline Jiayugufen & 300117 & Zhejiangdingli & 603338 \\
\hline Dafukeji & 300134 & Weiminghuanbao & 603568 \\
\hline Yongqinghuanbao & 300187 & Xinwangda & 300207 \\
\hline Qianshanyaoji & 300216 & Dongfangredian & 300217 \\
\hline Meichengkeji & 300237 & Dianzhenduan & 300244 \\
\hline Chanshanyaoye & 300255 & Jinduankeji & 300258 \\
\hline Baanshuiwu & 300262 & Hejiagufen & 300273 \\
\hline Yangguangdianyuan & 300274 & Sannuoshenwu & 300298 \\
\hline Zhongjizhuangbei & 300308 & Bohuichuangxin & 300318 \\
\hline Jinmokeji & 300334 & Mengcaoshentai & 300355 \\
\hline Xuelanghuanjing & 300385 & Zhonglaigufen & 300393 \\
\hline Feilihua & 300395 & Huannengkeji & 300425 \\
\hline Sitongxincai & 300428 & Shanheyaopu & 300452 \\
\hline Maikeshanwu & 300463 & Zhongfeigufen & 300489 \\
\hline Meishangshentai & 300495 & Gaolangufen & 300499 \\
\hline Wandongyiliao & 600055 & Huarunshuanghe & 600062 \\
\hline Yutongkeche & 600066 & Jinhuagufen & 600080 \\
\hline Yongdinggufen & 600105 & Beifangxitu & 600111 \\
\hline Juhuagufen & 600160 & Jiangsuwuzhong & 600200 \\
\hline Guangshengyouse & 600259 & Haizhengyaoye & 600267 \\
\hline Guodiannanzi & 600268 & Hengruiyiyao & 600276 \\
\hline Taihuagufen & 600281 & Shiyinggufen & 603688 \\
\hline Hangfakeji & 600391 & Hanlianhuanjing & 600323 \\
\hline Changjiangtongxin & 600345 & Lianchuangguangdian & 600363 \\
\hline Ningboyunshen & 600366 & Shangongjintai & 600385 \\
\hline Wukuangziben & 600390 & Sanyouhuagong & 600409 \\
\hline Jianghuiqiche & 600418 & Peilingdianli & 600452 \\
\hline Baotaigufen & 600456 & Guiyanboye & 600459 \\
\hline Laobaixing & 603883 & Fenhuotongxin & 600498 \\
\hline Zhongtiankeji & 600522 & Changyuanjituan & 600525 \\
\hline Feidahuanbao & 600526 & Xiamengwuye & 600549 \\
\hline Tiandikeji & 600582 & Nanjingxiongmao & 600775 \\
\hline Shangchaigufen & 600841 & Hangfadongli & 600893 \\
\hline
\end{tabular}


Table 2: Input,output indexes and related raw datas

\begin{tabular}{|c|c|c|c|c|c|c|}
\hline \multirow{2}{*}{$\begin{array}{c}\text { Company } \\
\text { abbreviation }\end{array}$} & \multicolumn{3}{|c|}{ Input indexes } & \multicolumn{3}{|c|}{ Output indexes } \\
\hline & $\begin{array}{c}\text { Equity finan- } \\
\text { cing net value } \\
\text { (Ten thousand } \\
\text { yuan) }\end{array}$ & $\begin{array}{c}\text { Ownership } \\
\text { concentration } \\
(\%)\end{array}$ & $\begin{array}{c}\text { Asset } \\
\text { liability } \\
\text { ratio }\end{array}$ & $\begin{array}{c}\text { Return on } \\
\text { equity }\end{array}$ & $\begin{array}{c}\text { Main } \\
\text { business } \\
\text { revenue } \\
\text { growth rate }\end{array}$ & Tobin Q \\
\hline Zhongguobaoan & 18000 & 11.9113 & 0.623791 & 0.051567 & 0.317839 & 1.029797 \\
\hline Shenzhennengyuan & 36830 & 47.8246 & 0.592068 & 0.056656 & 0.016903 & 0.447504 \\
\hline Dongxulantian & 12140 & 30.9812 & 0.365806 & 0.015992 & 1.265375 & 0.950595 \\
\hline Desaidianchi & 6436 & 45.2277 & 0.708479 & 0.233108 & 0.034411 & 1.677195 \\
\hline Tefaxinxi & 53460.62 & 39.1841 & 0.594942 & 0.111641 & 0.882775 & 1.565169 \\
\hline Haiwangshenwu & 9667.6 & 45.9346 & 0.647212 & 0.084867 & 0.223803 & 1.001336 \\
\hline Fenyuanyaoye & 45325 & 11.4827 & 0.537108 & 0.039653 & 0.308429 & 1.615621 \\
\hline Xujidianqi & 44700 & 41.276 & 0.472021 & 0.124559 & 0.307734 & 1.279725 \\
\hline Yingtejituan & 4646.4 & 21.5432 & 0.757153 & 0.113082 & 0.115792 & 0.656154 \\
\hline Zhongyuanhuanbao & 15075 & 56.618 & 0.152379 & 0.056745 & 0.807481 & 1.82053 \\
\hline Wanxiangqianchao & 11100 & 51.5291 & 0.589862 & 0.188514 & 0.053155 & 2.641354 \\
\hline Fenhuagaoke & 11002.5 & 20.0286 & 0.316424 & 0.031979 & 0.430391 & 1.30635 \\
\hline Huitianredian & 12719.46 & 35.1048 & 0.705711 & 0.042107 & 0.166339 & 0.700617 \\
\hline Yingluohua & 28325 & 39.3785 & 0.20797 & 0.01569 & 0.465252 & 2.841968 \\
\hline Zhongguangheji & 23625 & 27.6 & 0.53008 & 0.060528 & 0.439343 & 0.760075 \\
\hline Huanruishiji & 24186.25 & 5.9062 & 0.178561 & 0.098234 & 53.968966 & 4.174999 \\
\hline Kaidishentai & 28683 & 28.4657 & 0.68962 & 0.025709 & 0.430543 & 0.605557 \\
\hline Xinxianghuaxian & 56752 & 30.1696 & 0.372869 & 0.032147 & 0.199627 & 1.370864 \\
\hline Zhongkesanhuan & 25215 & 23.1744 & 0.133647 & 0.078054 & 0.011009 & 2.544025 \\
\hline Zhongtaiqiche & 30681.79 & 19.9883 & 0.473969 & 0.04028 & 0.041599 & 1.852857 \\
\hline Huagongkeji & 40680 & 32.3575 & 0.417369 & 0.073051 & 0.264986 & 2.496118 \\
\hline Jingxinyaoye & 16517 & 23.1578 & 0.262634 & 0.089321 & 0.324762 & 2.198813 \\
\hline Xinhaiyi & 13490.32 & 18.0506 & 0.62116 & 0.028052 & 0.091058 & 1.814412 \\
\hline Jinzhikeji & 22973 & 36.916 & 0.644611 & 0.105423 & 0.509782 & 1.472001 \\
\hline Laibaogaoke & 93265.7 & 20.8423 & 0.199965 & 0.059913 & 0.383746 & 1.707126 \\
\hline Wohuayiyao & 17907 & 50.2671 & 0.18847 & 0.107317 & 0.200293 & 8.440842 \\
\hline Sanweitongxin & 16648.17 & 19.0872 & 0.621308 & 0.025444 & 0.143054 & 1.679945 \\
\hline Yinlungufen & 23043.88 & 11.156 & 0.466098 & 0.105559 & 0.145714 & 1.457458 \\
\hline Tuobangufen & 17327.23 & 19.6085 & 0.32204 & 0.083375 & 0.263597 & 2.204443 \\
\hline Beiweikeji & 20715.509 & 21.2504 & 0.090645 & 0.071153 & 1.037182 & 3.988281 \\
\hline Laiyinshenwu & 15016.1 & 17.5723 & 0.652109 & 0.082234 & 0.110749 & 2.224834 \\
\hline Tuorixinneng & 41068.4 & 32.5529 & 0.437158 & 0.047604 & 0.568097 & 1.156847 \\
\hline Guanxunkeji & 61214.91 & 45.4344 & 0.395116 & 0.094016 & 0.292752 & 3.416419 \\
\hline Yataigufen & 42211.337 & 38.8217 & 0.4493 & 0.055966 & 0.117497 & 2.110095 \\
\hline Gelinmei & 70353.976 & 12.54 & 0.622371 & 0.041603 & 0.531296 & 0.999681 \\
\hline Hezhongsizhuang & 104927.53 & 39.4551 & 0.270369 & 0.027372 & 0.545808 & 2.467085 \\
\hline Siweituxin & 136777.3 & 12.2128 & 0.230614 & 0.036656 & 0.052553 & 5.006329 \\
\hline Duofuduo & 99084.837 & 13.9279 & 0.452753 & 0.165225 & 0.3093 & 3.259756 \\
\hline Kanshengufen & 66022.47 & 15.5804 & 0.698482 & 0.099706 & 0.287662 & 1.591019 \\
\hline Shuanghuanchuangdong & 77277.998 & 8.8614 & 0.228187 & 0.061629 & 0.247183 & 1.965198 \\
\hline Rongjiruanjian & 90566.32 & 20.6293 & 0.338254 & 0.017677 & 0.126668 & 3.951408 \\
\hline Jangfencicai & 59961.75 & 18.4646 & 0.577755 & 0.046733 & 1.475008 & 0.945552 \\
\hline Yamadun & 146868 & 45 & 0.493956 & 0.007921 & 0.27809 & 1.549758 \\
\hline Teruide & 77928.3 & 43.9969 & 0.748315 & 0.065754 & 1.034825 & 1.473806 \\
\hline
\end{tabular}




\begin{tabular}{|c|c|c|c|c|c|c|}
\hline Tianlongguangqi & 37392.79 & 42.1827 & 0.522712 & 0.150541 & 0.734491 & 2.84242 \\
\hline Huitianxincai & 57117.407 & 23.2827 & 0.134061 & 0.061031 & 0.160359 & 2.741069 \\
\hline Shuzizhengtong & 70255.3 & 30.4462 & 0.385291 & 0.098264 & 0.485614 & 3.133993 \\
\hline Yichengxinneng & 148008 & 20.0219 & 0.476753 & 0.008974 & 0.405479 & 0.791892 \\
\hline Dongfengrishen & 183757.98 & 32.5652 & 0.60289 & 0.183408 & 0.334125 & 1.116291 \\
\hline Xianhehuanbao & 62650.328 & 13.8599 & 0.162212 & 0.078113 & 0.256952 & 2.816268 \\
\hline Shenwuhuanbao & 110894.32 & 42.6771 & 0.487197 & 0.27446 & 1.572772 & 5.019875 \\
\hline Zhendongzhiyao & 130505.44 & 43.7861 & 0.233178 & 0.036636 & 0.451311 & 1.480393 \\
\hline Zhongdianhuanbao & 53860.62 & 28.9767 & 0.336518 & 0.102676 & 0.06689 & 2.9211 \\
\hline Chulingxinxi & 22050.3 & 42.7341 & 0.098137 & 0.082983 & 0.229803 & 4.049243 \\
\hline Tianhaohuanjing & 60990.82 & 21.2635 & 0.529938 & 0.013597 & 0.770685 & 0.958072 \\
\hline Kanxinxincai & 26700 & 21.3127 & 0.192468 & 0.13107 & 0.268388 & 2.678145 \\
\hline Shangqijituan & 208200 & 74.295 & 0.601955 & 0.186995 & 0.128313 & 0.437754 \\
\hline Dongkuigufen & 43199.69 & 19.4549 & 0.148709 & 0.074687 & 0.072161 & 2.585874 \\
\hline Zhongguoweixin & 12370 & 51.017 & 0.4703 & 0.080102 & 0.163146 & 3.402302 \\
\hline Mingjiangshuidian & 17569 & 23.9211 & 0.565189 & 0.153201 & 0.214414 & 2.286302 \\
\hline Futianqiche & 31000 & 27.0653 & 0.646346 & 0.02686 & 0.368691 & 0.382292 \\
\hline Yaxingkeche & 36999.8 & 51 & 0.956045 & 0.319506 & 0.684865 & 0.737739 \\
\hline Hongduhangkong & 87827 & 43.7703 & 0.522279 & 0.002468 & 0.307081 & 1.32524 \\
\hline Zhenhuanzhonggong & 83800 & 28.8281 & 0.728936 & 0.018641 & 0.046222 & 0.324244 \\
\hline Hangtiandongli & 22857.772 & 28.7781 & 0.39091 & 0.013658 & 0.199757 & 3.080362 \\
\hline Kunyaojituan & 39343 & 29.7873 & 0.33139 & 0.113377 & 0.037617 & 1.972355 \\
\hline Hengtongguangdian & 38016.6 & 19.3351 & 0.656001 & 0.224366 & 0.423001 & 1.173695 \\
\hline Guihanggufen & 32755.42 & 37.0069 & 0.384845 & 0.082063 & 0.050131 & 1.752411 \\
\hline Yijinguangdian & 28587.636 & 30.3608 & 0.572383 & 0.118439 & 0.050501 & 1.232354 \\
\hline Guangyuyuan & 6750 & 23.2198 & 0.193013 & 0.089001 & 1.187008 & 5.51039 \\
\hline ShensangdaA & 8400 & 27.8079 & 0.18994 & 0.021402 & 0.093641 & 3.226157 \\
\hline Xugongjixie & 11040 & 42.5567 & 0.43458 & 0.016345 & 0.010659 & 0.538602 \\
\hline Liugong & 20000 & 34.9758 & 0.45215 & 0.012268 & 0.090789 & 0.399605 \\
\hline Haimaqiche & 16000 & 28.7966 & 0.1066 & 0.001935 & 0.114369 & 0.484404 \\
\hline Qidiguhan & 5800 & 18.6099 & 0.55682 & 0.029638 & 0.022667 & 6.958307 \\
\hline Shantuigufen & 37300.6 & 12.8127 & 0.53704 & 0.033263 & 0.290749 & 0.740825 \\
\hline Xinyegufen & 65280 & 23.591 & 0.47083 & 0.061276 & 0.142051 & 1.935407 \\
\hline Xinhuazhiyao & 3275 & 34.4595 & 0.56293 & 0.041142 & 0.146104 & 1.200706 \\
\hline Zhonghangfeiji & 35700 & 38.1795 & 0.53861 & 0.023972 & 0.093937 & 1.500922 \\
\hline Qinchuangjichuang & 19783 & 4.999 & 0.48565 & 0.00598 & 0.26126 & 0.751772 \\
\hline Yingxingnengyuan & 28140 & 14.6453 & 0.62288 & 0.008091 & 0.078713 & 0.459694 \\
\hline Ankaiqiche & 32820 & 21.1339 & 0.82949 & 0.041277 & 0.22801 & 0.509507 \\
\hline Faershen & 36948.6 & 21.0656 & 0.75692 & 0.144655 & 0.12084 & 0.519541 \\
\hline Yunneidongli & 37500 & 30.9655 & 0.44611 & 0.051304 & 0.381352 & 0.88804 \\
\hline Shandahuate & 13499 & 20.7161 & 0.12023 & 0.168022 & 0.181025 & 3.059428 \\
\hline Hebeixuangong & 19567.33 & 35.5402 & 0.7105 & 0.005127 & 0.02375 & 3.36523 \\
\hline Zhongguozhongqi & 32396.54 & 63.7759 & 0.73288 & 0.096596 & 0.07623 & 0.444266 \\
\hline Fuosukeji & 58045 & 5.8586 & 0.49031 & 0.071475 & 0.036139 & 1.489305 \\
\hline Jiuzhitang & 34530 & 5.8439 & 0.08758 & 0.034818 & 0.114623 & 3.933827 \\
\hline Shirongzhaoye & 17737.83 & 53.5709 & 0.20849 & 0.108033 & 0.432934 & 1.077128 \\
\hline Zhouyankeji & 14783.99 & 39.5579 & 0.33056 & 0.034476 & 0.083552 & 1.775413 \\
\hline Hengdiancidong & 61040.62 & 50.146 & 0.31203 & 0.111907 & 0.128831 & 1.961213 \\
\hline Zhonggangtianyuan & 12829.22 & 25.9393 & 0.16786 & 0.019791 & 0.11988 & 4.923638 \\
\hline Suzhougude & 22537.68 & 34.284 & 0.12605 & 0.087356 & 0.211722 & 3.80147 \\
\hline Longjigufen & 151310.5 & 14.9446 & 0.38142 & 0.061057 & 0.95973 & 1.670124 \\
\hline Zhongcaijieneng & 25120 & 2.2383 & 0.39708 & 0.081635 & 0.088168 & 2.091867 \\
\hline
\end{tabular}




\begin{tabular}{|c|c|c|c|c|c|c|}
\hline Wowehecai & 20823.57 & 2.806 & 0.46708 & 0.018855 & 0.119996 & 1.851254 \\
\hline Yunhaijinshu & 49632.15 & 6.4141 & 0.57318 & 0.011782 & 0.310188 & 2.036891 \\
\hline Zhengtongdianzi & 23343.26 & 5.779 & 0.43747 & 0.017756 & 0.700349 & 1.784756 \\
\hline Feimaguoji & 25387.15 & 50.0595 & 0.84064 & 0.072063 & 0.073705 & 0.911288 \\
\hline Aotexun & 37539.58 & 57.5726 & 0.27216 & 0.024992 & 0.068753 & 5.328808 \\
\hline Aoweitongxin & 21531.88 & 18.4978 & 0.22478 & 0.011085 & 0.23733 & 6.246577 \\
\hline Dahuagufen & 38955.3 & 10.3138 & 0.18514 & 0.233542 & 0.302168 & 2.581213 \\
\hline Chuanrungufen & 22181.79 & 3.8122 & 0.02606 & 0.003113 & 0.025215 & 2.452324 \\
\hline Zhongdianxinlong & 24013.97 & 5.2163 & 0.1709 & 0.008062 & 0.074614 & 1.542406 \\
\hline Dongfangyuanlin & 80103.85 & 8.2513 & 0.60675 & 0.09416 & 0.275175 & 2.016332 \\
\hline Gelinmei & 70353.98 & 10.3159 & 0.53233 & 0.003037 & 0.471734 & 1.109946 \\
\hline Longjijixie & 50896 & 45.5516 & 0.30383 & 0.03472 & 0.066615 & 1.908261 \\
\hline Dongshanjimi & 95882.38 & 8.7742 & 0.76089 & 0.004494 & 0.361346 & 1.097664 \\
\hline Neimengyiji & 34527 & 23.6185 & 0.4673 & 0.064681 & 24.638863 & 2.927052 \\
\hline Shenlutongxin & 43002.5 & 4.5006 & 0.17994 & 0.030051 & 0.099744 & 4.009343 \\
\hline Haigetongxin & 314314.4 & 16.9693 & 0.26216 & 0.082313 & 0.041283 & 2.764868 \\
\hline Fuchunhuanbao & 133771.2 & 34.7541 & 0.20614 & 0.1019 & 0.192276 & 2.220042 \\
\hline Keshida & 88362.82 & 60.1006 & 0.29619 & 0.132879 & 0.107002 & 3.596084 \\
\hline Tianshunfenneng & 122682.9 & 29.8115 & 0.22284 & 0.058555 & 0.108446 & 1.573325 \\
\hline Yataikeji & 154722.5 & 10.623 & 0.06154 & 0.07064 & 0.134139 & 2.717388 \\
\hline Yishenyaoye & 103922.1 & 9.771 & 0.40291 & 0.028825 & 0.077862 & 1.559103 \\
\hline Qinxinhuanjiang & 159048.6 & 45.0273 & 0.58945 & 0.217156 & 0.45448 & 1.887238 \\
\hline Shenyanggufen & 43837.11 & 2.8958 & 0.41865 & 0.045569 & 0.119271 & 2.056385 \\
\hline Daomingguangxue & 56736.49 & 42.182 & 0.17677 & 0.004946 & 0.036836 & 4.526761 \\
\hline Maoshuodianyuan & 41418.55 & 7.5847 & 0.42547 & 0.015636 & 0.020701 & 1.932026 \\
\hline Jingweigufen & 143213.8 & 30 & 0.43974 & 0.093117 & 0.199524 & 1.331809 \\
\hline Teyiyaoye & 32180.69 & 2.9 & 0.44267 & 0.075389 & 0.18795 & 3.176194 \\
\hline Ankeshenwu & 32109.5 & 6.7488 & 0.25408 & 0.106903 & 0.156789 & 7.523596 \\
\hline Jiqiren & 57590 & 25.27 & 0.14804 & 0.072172 & 0.204218 & 5.255439 \\
\hline Meitainuo & 55130 & 5.867 & 0.44249 & 0.013416 & 0.001622 & 2.410953 \\
\hline Hekanxinneng & 96456.42 & 21.7151 & 0.19407 & 0.039542 & 0.052915 & 1.881521 \\
\hline Yujingongshi & 74502.18 & 20.4566 & 0.21699 & 0.018039 & 0.464152 & 1.643184 \\
\hline Nandudianyuan & 196564.9 & 4.3561 & 0.27284 & 0.022368 & 0.032202 & 1.862394 \\
\hline Danshengkeji & 65537.19 & 27.0571 & 0.38001 & 0.025615 & 0.41984 & 4.759231 \\
\hline Shwnyunhuanbao & 51262.02 & 6.7223 & 0.47692 & 0.008596 & 0.524326 & 1.247397 \\
\hline Jiayugufen & 67769.9 & 39.6643 & 0.6294 & 0.064815 & 0.0408 & 1.067788 \\
\hline Zhenjiangdingli & 43987.43 & 1.575 & 0.18195 & 0.160318 & 0.415431 & 5.58102 \\
\hline Dafukeji & 186988.5 & 43.3888 & 0.21451 & 0.028971 & 0.082131 & 2.528019 \\
\hline Weiminghuanbao & 45147.32 & 1.6236 & 0.06583 & 0.247014 & 0.09413 & 5.270439 \\
\hline Yongqinghuanbao & 61352.57 & 58.2045 & 0.39453 & 0.065618 & 0.291912 & 3.375329 \\
\hline Xinwangda & 82334.43 & 6.2204 & 0.71533 & 0.22284 & 0.363935 & 2.80671 \\
\hline Qianshanyaoji & 46468.2 & 3.4452 & 0.65659 & 0.196326 & 0.868597 & 3.403831 \\
\hline Dongfangdianre & 55924.64 & 3.9023 & 0.17367 & 0.032649 & 0.003564 & 2.56007 \\
\hline Meichengkeji & 33231.09 & 3.7468 & 0.24912 & 0.048871 & 0.367727 & 2.276939 \\
\hline Dianzhenduan & 27027.73 & 8.3066 & 0.55446 & 0.039967 & 0.299982 & 3.347799 \\
\hline Chanshangyaoye & 69726.11 & 12.5569 & 0.25662 & 0.074874 & 0.28552 & 2.486892 \\
\hline Jingduankeji & 58793.76 & 48.3557 & 0.23397 & 0.092779 & 0.156354 & 2.923013 \\
\hline Baanshuiwu & 26742.12 & 10.4186 & 0.44756 & 0.062255 & 0.408375 & 2.176984 \\
\hline Hejiagufen & 61004.08 & 5.0013 & 0.2824 & 0.044699 & 0.119007 & 3.763279 \\
\hline Yangguangdianyuan & 127124.4 & 7.9717 & 0.47948 & 0.098043 & 0.485882 & 1.553448 \\
\hline
\end{tabular}




\begin{tabular}{|c|c|c|c|c|c|c|}
\hline Sannuoshenwu & 58083.6 & 27.6498 & 0.1304 & 0.094702 & 0.234857 & 4.712694 \\
\hline Zhongjizhuangbei & 29766.16 & 46.0071 & 0.12081 & 0.01809 & 0.084099 & 4.693377 \\
\hline Bohuichuangxin & 35854.15 & 19.8865 & 0.19687 & 0.016975 & 0.192963 & 3.820974 \\
\hline Jinmokeji & 44544.75 & 23.1869 & 0.38736 & 0.034106 & 0.210806 & 2.407568 \\
\hline Mengcaoshentai & 37361.41 & 5.9687 & 0.50505 & 0.09888 & 0.600747 & 1.855393 \\
\hline Xuelanghuanjing & 25810.54 & 1.0918 & 0.48881 & 0.113478 & 0.298417 & 2.804849 \\
\hline Zhonglaigufen & 35000 & 7.6141 & 0.51244 & 0.221942 & 0.893895 & 2.596604 \\
\hline Feilihua & 26983.01 & 7.0122 & 0.21285 & 0.115276 & 0.119594 & 5.003353 \\
\hline Huannengkeji & 24403 & 1.2456 & 0.09319 & 0.031894 & 0.308065 & 4.260348 \\
\hline Sitongxincai & 26842.62 & 0.2054 & 0.13374 & 0.111696 & 0.207206 & 8.550455 \\
\hline Shanheyaopu & 14868.6 & 1.8982 & 0.21451 & 0.118519 & 0.085339 & 9.237657 \\
\hline Maikeshenwu & 99732 & 5.9588 & 0.08749 & 0.14305 & 0.137017 & 5.640249 \\
\hline Zhongfeigufen & 16203.37 & 6.7488 & 0.268 & 0.063789 & 0.138595 & 5.551527 \\
\hline Meishangshentai & 49591.66 & 5.1021 & 0.33097 & 0.053404 & 0.193698 & 4.627519 \\
\hline Gaolaigufen & 22761.43 & 1.9472 & 0.49794 & 0.120104 & 0.305244 & 5.135788 \\
\hline Wandongyiliao & 12330 & 46.6818 & 0.15173 & 0.058092 & 0.010364 & 3.419443 \\
\hline Huanrunshuanghe & 30503 & 38.8981 & 0.11882 & 0.098426 & 0.013767 & 1.78957 \\
\hline Yutongkeche & 33075 & 27.114 & 0.60509 & 0.303712 & 0.155955 & 1.751181 \\
\hline Jinhuangufen & 17880 & 15.7225 & 0.22583 & 0.026587 & 0.276149 & 2.53229 \\
\hline Yongdinggufen & 23996.03 & 25.7401 & 0.21915 & 0.052393 & 0.041948 & 2.727364 \\
\hline Beifangxitu & 34240 & 30 & 0.25873 & 0.084874 & 0.05082 & 2.841912 \\
\hline Juhuagufen & 44341.68 & 48.7474 & 0.09062 & 0.006217 & 0.049251 & 1.927764 \\
\hline Jangsuwuzhong & 25047.5 & 17.0103 & 0.19168 & 0.022737 & 0.147961 & 2.171001 \\
\hline Guangshengyouse & 29710.11 & 37.2164 & 0.37972 & 0.025531 & 2.337913 & 3.147939 \\
\hline Haizhengyaoye & 45979.83 & 33.2235 & 0.44983 & 0.000534 & 0.035507 & 0.700826 \\
\hline Guodiannanzi & 30771 & 50.2603 & 0.74765 & 0.086113 & 0.112207 & 0.488345 \\
\hline Hengruiyiyao & 46660 & 24.3076 & 0.08688 & 0.22595 & 0.209272 & 7.586455 \\
\hline Taihuagufen & 55755 & 43.4783 & 0.69624 & 0.078889 & 0.17965 & 1.62128 \\
\hline Shiyinggufen & 33084.48 & 2.828 & 0.04865 & 0.07237 & 0.081654 & 3.683754 \\
\hline Hangfakeji & 24523 & 36.0184 & 0.61126 & 0.031833 & 0.088985 & 2.336412 \\
\hline Hanlanhuanjing & 41825 & 17.9806 & 0.44463 & 0.035094 & 0.143528 & 0.907461 \\
\hline Changjiangtongxin & 35460 & 28.6274 & 0.07628 & 0.019998 & 0.369324 & 2.519341 \\
\hline Lianchuangguangdain & 38722 & 21.7288 & 0.22522 & 0.08026 & 0.168225 & 2.196961 \\
\hline Ningboshenrun & 34845.57 & 31.3721 & 0.1723 & 0.137232 & 0.370272 & 2.053032 \\
\hline Shandongjintai & 3977.72 & 17.3819 & 8.38 & 0.025617 & 0.051392 & 17.658202 \\
\hline Wukuangziben & 58120 & 27.8393 & 0.10632 & 0.003036 & 0.278969 & 2.069426 \\
\hline Sanyouhuangong & 57694.5 & 39.9839 & 0.4762 & 0.037353 & 0.441365 & 0.803604 \\
\hline Jianghuaiqiche & 84119.15 & 7.0963 & 0.64123 & 0.073875 & 0.144266 & 0.511175 \\
\hline Peilingdianli & 24348.16 & 51.6438 & 0.76181 & 0.188405 & 0.332232 & 2.104195 \\
\hline Baotaigufen & 31088.4 & 56.0419 & 0.47841 & 0.018563 & 0.08157 & 1.150653 \\
\hline Guiyanboye & 25939.8 & 39.3433 & 0.41914 & 0.038357 & 0.148653 & 1.971349 \\
\hline Laobaixing & 101002.8 & 2.0548 & 0.50295 & 0.034679 & 0.273318 & 2.917035 \\
\hline Fenghuotongxin & 179734.2 & 46.5749 & 0.70317 & 0.054282 & 0.370349 & 1.380452 \\
\hline Zhongtiankeji & 35992 & 16.5882 & 0.33742 & 0.078633 & 0.268934 & 1.429016 \\
\hline Changyuanjituan & 18085.6 & 3.9149 & 0.59015 & 0.038324 & 0.211132 & 1.265562 \\
\hline Feidahuanbao & 27297.22 & 17.6519 & 0.64511 & 0.010392 & 0.154221 & 0.918951 \\
\hline Xiamengwuye & 33354.83 & 26.0363 & 0.48819 & 0.030018 & 0.563182 & 1.751385 \\
\hline Tiandikeji & 30222 & 36.3103 & 0.39303 & 0.022878 & 0.175307 & 0.54382 \\
\hline Nanjingxiongmao & 11199.3 & 26.4147 & 0.09628 & 0.02091 & 1.0991 & 2.665993 \\
\hline Shangchaigufen & 14335 & 48.0509 & 0.37862 & 0.027448 & 0.175091 & 1.616131 \\
\hline Hangfadongli & 29744 & 29.7823 & 0.32432 & 0.035797 & 0.007234 & 1.325377 \\
\hline Bohaihuosai & 30397 & 18.191 & 0.26409 & 0.001953 & 0.222484 & 1.449027 \\
\hline
\end{tabular}


Table 3: Evaluation results of equity financing efficiency of listed companies in strategic emerging industries

\begin{tabular}{|c|c|c|c|c|}
\hline Company abbreviation & $\begin{array}{c}\text { Comprehensive } \\
\text { efficiency }\end{array}$ & $\begin{array}{c}\text { Pure technical } \\
\text { efficiency }\end{array}$ & Scale efficiency & Returns to scale \\
\hline Zhongguobaoan & 0.291 & 0.589 & 0.494 & drs \\
\hline Shenzhennengyuan & 1.000 & 1.000 & 1.000 & - \\
\hline Dongxulantian & 0.464 & 0.663 & 0.700 & drs \\
\hline Desaidianchi & 0.472 & 0.876 & 0.539 & drs \\
\hline Tefaxinxi & 0.258 & 0.611 & 0.422 & drs \\
\hline Haiwangshenwu & 0.447 & 0.744 & 0.600 & drs \\
\hline Fenyuanyaoye & 0.234 & 0.441 & 0.532 & drs \\
\hline Xujidianqi & 0.305 & 0.619 & 0.493 & drs \\
\hline Yingtejituan & 0.513 & 0.858 & 0.598 & drs \\
\hline Zhongyuanhuanbao & 0.355 & 0.938 & 0.378 & drs \\
\hline Wanxiangqianchao & 0.267 & 0.895 & 0.299 & drs \\
\hline Fenhuagaoke & 0.210 & 0.398 & 0.528 & drs \\
\hline Huitianredian & 0.543 & 0.850 & 0.639 & drs \\
\hline Yingluohua & 0.240 & 0.728 & 0.329 & drs \\
\hline Zhongguangheji & 0.370 & 0.591 & 0.625 & drs \\
\hline Huanruishiji & 0.035 & 0.125 & 0.284 & drs \\
\hline Kaidishentai & 0.619 & 0.850 & 0.728 & drs \\
\hline Xinxianghuaxian & 0.327 & 0.588 & 0.555 & drs \\
\hline Zhongkesanhuan & 0.508 & 0.624 & 0.813 & drs \\
\hline Zhongtaiqiche & 0.362 & 0.465 & 0.777 & drs \\
\hline Huagongkeji & 0.172 & 0.533 & 0.323 & drs \\
\hline Jingxinyaoye & 0.121 & 0.368 & 0.329 & drs \\
\hline Xinhaiyi & 0.355 & 0.489 & 0.725 & drs \\
\hline Jinzhikeji & 0.259 & 0.587 & 0.441 & drs \\
\hline Laibaogaoke & 0.263 & 0.470 & 0.561 & drs \\
\hline Wohuayiyao & 0.125 & 0.761 & 0.165 & drs \\
\hline Sanweitongxin & 0.343 & 0.521 & 0.659 & drs \\
\hline Yinlungufen & 0.175 & 0.377 & 0.464 & drs \\
\hline Tuobangufen & 0.107 & 0.322 & 0.333 & drs \\
\hline Beiweikeji & 0.076 & 0.341 & 0.222 & drs \\
\hline Laiyinshenwu & 0.253 & 0.420 & 0.603 & drs \\
\hline Tuorixinneng & 0.317 & 0.607 & 0.522 & drs \\
\hline Guanxunkeji & 0.184 & 0.708 & 0.260 & drs \\
\hline Yataigufen & 0.257 & 0.656 & 0.392 & drs \\
\hline Gelinmei & 0.346 & 0.658 & 0.525 & drs \\
\hline Hezhongsizhuang & 0.342 & 0.790 & 0.433 & drs \\
\hline Siweituxin & 0.481 & 0.636 & 0.756 & drs \\
\hline Duofuduo & 0.148 & 0.402 & 0.369 & drs \\
\hline Kanshengufen & 0.195 & 0.566 & 0.345 & drs \\
\hline Shuanghuanchuangdong & 0.219 & 0.355 & 0.616 & drs \\
\hline Rongjiruanjian & 0.329 & 0.590 & 0.557 & drs \\
\hline Jangfencicai & 0.296 & 0.593 & 0.499 & drs \\
\hline Yamadun & 0.901 & 1.000 & 0.901 & drs \\
\hline Teruide & 0.338 & 0.814 & 0.415 & drs \\
\hline Tianlongguangqi & 0.159 & 0.611 & 0.261 & drs \\
\hline Huitianxincai & 0.176 & 0.417 & 0.422 & drs \\
\hline Shuzizhengtong & 0.137 & 0.496 & 0.276 & drs \\
\hline Yichengxinneng & 1.000 & 1.000 & 1.000 & - \\
\hline Dongfengrishen & 0.513 & 0.841 & 0.610 & drs \\
\hline Xianhehuanbao & 0.136 & 0.300 & 0.454 & drs \\
\hline Shenwuhuanbao & 0.096 & 0.588 & 0.163 & drs \\
\hline Zhendongzhiyao & 0.519 & 0.871 & 0.596 & drs \\
\hline Zhongdianhuanbao & 0.230 & 0.498 & 0.461 & drs \\
\hline Chulingxinxi & 0.152 & 0.672 & 0.226 & drs \\
\hline Tianhaohuanjing & 0.551 & 0.672 & 0.820 & drs \\
\hline Kanxinxincai & 0.092 & 0.313 & 0.293 & drs \\
\hline
\end{tabular}




\begin{tabular}{|c|c|c|c|c|}
\hline Shangqijituan & 1.000 & 1.000 & 1.000 & - \\
\hline Dongkuigufen & 0.188 & 0.355 & 0.530 & drs \\
\hline Zhongguoweixin & 0.206 & 0.816 & 0.253 & drs \\
\hline Mingjiangshuidian & 0.142 & 0.378 & 0.376 & drs \\
\hline Futianqiche & 0.765 & 0.860 & 0.890 & drs \\
\hline Yaxingkeche & 0.637 & 1.000 & 0.637 & drs \\
\hline Hongduhangkong & 0.847 & 1.000 & 0.847 & drs \\
\hline Zhenhuanzhonggong & 1.000 & 1.000 & 1.000 & - \\
\hline Hangtiandongli & 0.181 & 0.562 & 0.321 & drs \\
\hline Kunyaojituan & 0.305 & 0.566 & 0.539 & drs \\
\hline Hengtongguangdian & 0.249 & 0.586 & 0.424 & drs \\
\hline Guihanggufen & 0.303 & 0.657 & 0.461 & drs \\
\hline Yijinguangdian & 0.369 & 0.568 & 0.651 & drs \\
\hline Guangyuyuan & 0.059 & 0.365 & 0.162 & drs \\
\hline ShensangdaA & 0.215 & 0.490 & 0.439 & drs \\
\hline Xugongjixie & 1.000 & 1.000 & 1.000 & - \\
\hline Liugong & 1.000 & 1.000 & 1.000 & - \\
\hline Haimaqiche & 1.000 & 1.000 & 1.000 & - \\
\hline Qidiguhan & 0.293 & 0.433 & 0.676 & drs \\
\hline Shantuigufen & 0.369 & 0.584 & 0.632 & drs \\
\hline Xinyegufen & 0.224 & 0.483 & 0.462 & drs \\
\hline Xinhuazhiyao & 0.359 & 0.680 & 0.528 & drs \\
\hline Zhonghangfeiji & 0.409 & 0.736 & 0.556 & drs \\
\hline Qinchuangjichuang & 0.683 & 0.726 & 0.941 & drs \\
\hline Yingxingnengyuan & 1.000 & 1.000 & 1.000 & - \\
\hline Ankaiqiche & 0.724 & 1.000 & 0.724 & drs \\
\hline Faershen & 0.648 & 0.920 & 0.704 & drs \\
\hline Yunneidongli & 0.372 & 0.607 & 0.613 & drs \\
\hline Shandahuate & 0.077 & 0.286 & 0.269 & drs \\
\hline Hebeixuangong & 1.000 & 1.000 & 1.000 & - \\
\hline Zhongguozhongqi & 1.000 & 1.000 & 1.000 & - \\
\hline Fuosukeji & 0.497 & 0.542 & 0.916 & drs \\
\hline Jiuzhitang & 0.093 & 0.172 & 0.540 & drs \\
\hline Shirongzhaoye & 0.459 & 0.814 & 0.563 & drs \\
\hline Zhouyankeji & 0.327 & 0.684 & 0.478 & drs \\
\hline Hengdiancidong & 0.292 & 0.755 & 0.386 & drs \\
\hline Zhonggangtianyuan & 0.171 & 0.460 & 0.372 & drs \\
\hline Suzhougude & 0.127 & 0.536 & 0.237 & drs \\
\hline Longjigufen & 0.401 & 0.703 & 0.571 & drs \\
\hline Zhongcaijieneng & 0.177 & 0.268 & 0.660 & drs \\
\hline Wowehecai & 0.279 & 0.334 & 0.834 & drs \\
\hline Yunhaijinshu & 0.340 & 0.468 & 0.728 & drs \\
\hline Zhengtongdianzi & 0.238 & 0.324 & 0.733 & drs \\
\hline Feimaguoji & 0.582 & 0.922 & 0.632 & drs \\
\hline Aotexun & 0.495 & 1.000 & 0.495 & drs \\
\hline Aoweitongxin & 0.077 & 0.372 & 0.208 & drs \\
\hline Dahuagufen & 0.064 & 0.178 & 0.360 & drs \\
\hline Chuanrungufen & 0.427 & 1.000 & 0.427 & irs \\
\hline Zhongdianxinlong & 0.191 & 0.255 & 0.747 & drs \\
\hline Dongfangyuanlin & 0.176 & 0.498 & 0.353 & drs \\
\hline Gelinmei & 0.742 & 0.849 & 0.875 & drs \\
\hline Longjijixie & 0.436 & 0.846 & 0.515 & drs \\
\hline Dongshanjimi & 0.998 & 1.000 & 0.998 & drs \\
\hline Neimengyiji & 0.128 & 0.412 & 0.311 & $\mathrm{drs}$ \\
\hline Shenlutongxin & 0.134 & 0.223 & 0.601 & drs \\
\hline Haigetongxin & 1.000 & 1.000 & 1.000 & - \\
\hline Fuchunhuanbao & 0.309 & 0.642 & 0.481 & drs \\
\hline Keshida & 0.310 & 0.876 & 0.354 & drs \\
\hline Tianshunfenneng & 0.458 & 0.689 & 0.665 & drs \\
\hline Yataikeji & 0.390 & 0.536 & 0.728 & drs \\
\hline Yishenyaoye & 0.516 & 0.646 & 0.798 & drs \\
\hline
\end{tabular}




\begin{tabular}{|c|c|c|c|c|}
\hline Qinxinhuanjiang & 0.288 & 0.724 & 0.398 & $\mathrm{drs}$ \\
\hline Shenyanggufen & 0.193 & 0.340 & 0.567 & drs \\
\hline Daomingguangxue & 1.000 & 1.000 & 1.000 & - \\
\hline Maoshuodianyuan & 0.532 & 0.573 & 0.929 & irs \\
\hline Jingweigufen & 0.405 & 0.707 & 0.572 & drs \\
\hline Teyiyaoye & 0.118 & 0.245 & 0.482 & drs \\
\hline Ankeshenwu & 0.066 & 0.156 & 0.423 & drs \\
\hline Jiqiren & 0.127 & 0.432 & 0.293 & drs \\
\hline Meitainuo & 1.000 & 1.000 & 1.000 & - \\
\hline Hekanxinneng & 0.490 & 0.591 & 0.830 & drs \\
\hline Yujingongshi & 0.319 & 0.465 & 0.687 & drs \\
\hline Nandudianyuan & 1.000 & 1.000 & 1.000 & - \\
\hline Danshengkeji & 0.154 & 0.547 & 0.281 & drs \\
\hline Shwnyunhuanbao & 0.471 & 0.535 & 0.880 & drs \\
\hline Jiayugufen & 0.647 & 0.841 & 0.769 & drs \\
\hline Zhenjiangdingli & 0.048 & 0.157 & 0.307 & drs \\
\hline Dafukeji & 0.764 & 1.000 & 0.764 & drs \\
\hline Weiminghuanbao & 0.074 & 0.147 & 0.505 & drs \\
\hline Yongqinghuanbao & 0.257 & 0.946 & 0.272 & drs \\
\hline Xinwangda & 0.122 & 0.443 & 0.276 & drs \\
\hline Qianshanyaoji & 0.086 & 0.330 & 0.260 & drs \\
\hline Dongfangdianre & 0.796 & 0.825 & 0.965 & drs \\
\hline Meichengkeji & 0.096 & 0.210 & 0.459 & drs \\
\hline Dianzhenduan & 0.164 & 0.281 & 0.583 & drs \\
\hline Chanshangyaoye & 0.161 & 0.319 & 0.503 & drs \\
\hline Jingduankeji & 0.227 & 0.750 & 0.303 & drs \\
\hline Baanshuiwu & 0.128 & 0.294 & 0.437 & drs \\
\hline Hejiagufen & 0.169 & 0.278 & 0.607 & drs \\
\hline Yangguangdianyuan & 0.313 & 0.631 & 0.495 & drs \\
\hline Sannuoshenwu & 0.122 & 0.439 & 0.279 & drs \\
\hline Zhongjizhuangbei & 0.396 & 0.830 & 0.477 & drs \\
\hline Bohuichuangxin & 0.120 & 0.390 & 0.307 & drs \\
\hline Jinmokeji & 0.168 & 0.448 & 0.374 & drs \\
\hline Mengcaoshentai & 0.126 & 0.369 & 0.343 & drs \\
\hline Xuelanghuanjing & 0.101 & 0.273 & 0.369 & drs \\
\hline Zhonglaigufen & 0.088 & 0.306 & 0.287 & drs \\
\hline Feilihua & 0.074 & 0.139 & 0.533 & drs \\
\hline Huannengkeji & 0.059 & 0.121 & 0.491 & drs \\
\hline Sitongxincai & 0.036 & 0.099 & 0.364 & drs \\
\hline Shanheyaopu & 0.050 & 0.074 & 0.678 & drs \\
\hline Maikeshenwu & 0.147 & 0.320 & 0.458 & drs \\
\hline Zhongfeigufen & 0.066 & 0.136 & 0.487 & drs \\
\hline Meishangshentai & 0.115 & 0.222 & 0.521 & drs \\
\hline Gaolaigufen & 0.082 & 0.180 & 0.457 & drs \\
\hline Wandongyiliao & 1.000 & 1.000 & 1.000 & - \\
\hline Huanrunshuanghe & 0.717 & 0.882 & 0.813 & drs \\
\hline Yutongkeche & 0.195 & 0.465 & 0.419 & drs \\
\hline Jinhuangufen & 0.106 & 0.293 & 0.363 & drs \\
\hline Yongdinggufen & 0.221 & 0.490 & 0.452 & drs \\
\hline Beifangxitu & 0.211 & 0.534 & 0.394 & drs \\
\hline Juhuagufen & 0.837 & 1.000 & 0.837 & drs \\
\hline Jangsuwuzhong & 0.140 & 0.323 & 0.432 & drs \\
\hline Guangshengyouse & 0.198 & 0.666 & 0.297 & drs \\
\hline Haizhengyaoye & 1.000 & 1.000 & 1.000 & - \\
\hline Guodiannanzi & 0.825 & 0.967 & 0.853 & drs \\
\hline Hengruiyiyao & 0.073 & 0.327 & 0.224 & drs \\
\hline Taihuagufen & 0.308 & 0.724 & 0.425 & drs \\
\hline Shiyinggufen & 0.080 & 0.118 & 0.677 & drs \\
\hline Hangfakeji & 0.333 & 0.652 & 0.511 & drs \\
\hline
\end{tabular}




\begin{tabular}{|c|c|c|c|c|}
\hline Hanlanhuanjing & 0.280 & 0.491 & 0.570 & drs \\
\hline Changjiangtongxin & 0.199 & 0.532 & 0.375 & drs \\
\hline Lianchuangguangdain & 0.133 & 0.355 & 0.373 & drs \\
\hline Ningboshenrun & 0.159 & 0.454 & 0.351 & drs \\
\hline Shandongjintai & 1.000 & 1.000 & 1.000 & - \\
\hline Wukuangziben & 0.381 & 0.643 & 0.593 & drs \\
\hline Sanyouhuangong & 0.554 & 0.819 & 0.677 & drs \\
\hline Jianghuaiqiche & 0.583 & 0.819 & 0.712 & drs \\
\hline Peilingdianli & 0.240 & 0.727 & 0.330 & drs \\
\hline Baotaigufen & 0.744 & 1.000 & 0.744 & drs \\
\hline Guiyanboye & 0.290 & 0.683 & 0.424 & drs \\
\hline Laobaixing & 0.306 & 0.514 & 0.594 & drs \\
\hline Fenghuotongxin & 0.574 & 1.000 & 0.574 & drs \\
\hline Zhongtiankeji & 0.129 & 0.325 & 0.395 & drs \\
\hline Changyuanjituan & 0.285 & 0.509 & 0.560 & drs \\
\hline Feidahuanbao & 0.645 & 0.779 & 0.828 & drs \\
\hline Xiamengwuye & 0.252 & 0.529 & 0.476 & drs \\
\hline Tiandikeji & 0.740 & 0.866 & 0.855 & drs \\
\hline Nanjingxiongmao & 0.156 & 0.467 & 0.334 & drs \\
\hline Shangchaigufen & 0.436 & 0.841 & 0.519 & $\mathrm{drs}$ \\
\hline Hangfadongli & 1.000 & 1.000 & 1.000 & - \\
\hline Bohaihuosai & 0.290 & 0.461 & 0.629 & $\mathrm{drs}$ \\
\hline Mean & 0.370 & 0.603 & 0.563 & \\
\hline
\end{tabular}

Among them, the "irs" indicates that the scale of compensation increases, "-" means that the scale compensation is constant, and "drs" represents diminishing returns of scale.

Table 4: The input redundancy and output insufficiency of each decision unit

\begin{tabular}{|c|c|c|c|c|c|c|}
\hline \multirow[t]{2}{*}{ Company abbreviation } & \multicolumn{3}{|c|}{ Input redundancy } & \multicolumn{3}{|c|}{ Output insufficiency } \\
\hline & $\begin{array}{c}\text { Equity finan- } \\
\text { cing net value } \\
\text { (Ten thousand } \\
\text { yuan) }\end{array}$ & $\begin{array}{c}\text { Ownership } \\
\text { concentration } \\
(\%)\end{array}$ & $\begin{array}{l}\text { Asset liability } \\
\text { ratio }\end{array}$ & Return on equity & $\begin{array}{l}\text { Main business } \\
\text { revenue } \\
\text { growth rate }\end{array}$ & Tobin Q \\
\hline Zhongguobaoan & 0.000 & -0.077 & 0.000 & 14121.371 & 10.265 & 0.436 \\
\hline Shenzhennengyuan & 0.000 & 0.000 & 0.000 & 0.000 & 0.000 & 0.000 \\
\hline Dongxulantian & 0.000 & -1.160 & 0.000 & 41564.597 & 15.716 & 0.186 \\
\hline Desaidianchi & -0.166 & 0.000 & -0.839 & 28397.577 & 6.402 & 0.100 \\
\hline Tefaxinxi & 0.000 & -0.790 & -0.306 & 34030.814 & 24.943 & 0.379 \\
\hline Haiwangshenwu & 0.000 & 0.147 & -0.082 & 21926.638 & 15.803 & 0.223 \\
\hline Fenyuanyaoye & 0.000 & -0.212 & 0.000 & 57466.912 & 23.2 & 0.681 \\
\hline Xujidianqi & 0.000 & -0.215 & -0.678 & 43096.172 & 25.399 & 0.290 \\
\hline Yingtejituan & -0.086 & 0.000 & 0.000 & 58409.159 & 4.171 & 0.125 \\
\hline Zhongyuanhuanbao & 0.000 & -0.718 & 0.000 & 56101.867 & 3.727 & 0.312 \\
\hline Wanxiangqianchao & -0.107 & 0.000 & -2.065 & 21917.104 & 6.070 & 0.069 \\
\hline Fenhuagaoke & 0.000 & -0.358 & 0.000 & 31116.628 & 30.285 & 0.478 \\
\hline Huitianredian & 0.000 & -0.108 & 0.000 & 50156.266 & 6.215 & 0.125 \\
\hline Yingluohua & 0.000 & -0.381 & -1.523 & 10608.972 & 14.749 & 0.196 \\
\hline Zhongguangheji & 0.000 & -0.374 & 0.000 & 31779.138 & 19.071 & 0.366 \\
\hline Huanruishiji & 0.000 & -53.880 & -0.446 & 169317.717 & 41.347 & 1.250 \\
\hline Kaidishentai & 0.000 & -0.379 & 0.000 & 46273.698 & 5.013 & 0.121 \\
\hline Xinxianghuaxian & 0.000 & -0.009 & 0.000 & 39750.568 & 21.132 & 0.261 \\
\hline Zhongkesanhuan & -0.028 & 0.000 & 0.000 & 15186.619 & 0.000 & 0.099 \\
\hline Zhongtaiqiche & 0.000 & 0.000 & 0.000 & 35230.028 & 22.951 & 0.544 \\
\hline Huagongkeji & 0.000 & -0.173 & -1.131 & 35587.270 & 28.307 & 0.365 \\
\hline Jingxinyaoye & 0.000 & -0.244 & -1.553 & 28407.906 & 39.830 & 0.452 \\
\hline Xinhaiyi & 0.000 & -0.035 & 0.000 & 48759.343 & 18.834 & 0.648 \\
\hline Jinzhikeji & 0.000 & -0.428 & -0.166 & 32083.533 & 25.976 & 0.454 \\
\hline Laibaogaoke & 0.000 & -0.206 & 0.000 & 105313.405 & 23.535 & 0.234 \\
\hline Wohuayiyao & 0.000 & -0.101 & -5.598 & 106357.017 & 15.803 & 0.251 \\
\hline Sanweitongxin & 0.000 & -0.087 & 0.000 & 46424.308 & 17.569 & 0.572 \\
\hline Yinlungufen & -0.049 & 0.000 & 0.000 & 43322.163 & 18.449 & 0.771 \\
\hline Tuobangufen & 0.000 & -0.180 & -0.766 & 36438.898 & 41.236 & 0.677 \\
\hline
\end{tabular}




\begin{tabular}{|c|c|c|c|c|c|c|}
\hline Beiweikeji & 0.000 & -0.951 & -0.053 & 65451.909 & 41.087 & 0.175 \\
\hline Laiyinshenwu & -0.010 & 0.000 & 0.000 & 38233.825 & 24.307 & 0.902 \\
\hline Tuorixinneng & 0.000 & -0.436 & 0.000 & 26562.311 & 21.055 & 0.283 \\
\hline Guanxunkeji & 0.000 & -0.201 & -2.009 & 25203.517 & 18.706 & 0.163 \\
\hline Yataigufen & 0.000 & -0.028 & -0.794 & 22175.391 & 20.395 & 0.236 \\
\hline Gelinmei & 0.000 & -0.435 & 0.000 & 36575.484 & 23.104 & 0.324 \\
\hline Hezhongsizhuang & 0.000 & -0.319 & -0.339 & 27886.559 & 10.486 & 0.194 \\
\hline Siweituxin & 0.000 & 0.000 & -2.558 & 78324.422 & 6.994 & 0.132 \\
\hline Duofuduo & 0.000 & -0.049 & -0.235 & 147662.734 & 24.308 & 0.675 \\
\hline Kanshengufen & -0.029 & -0.216 & 0.000 & 50556.718 & 26.488 & 0.535 \\
\hline Shuanghuanchuangdong & 0.000 & 0.000 & 0.000 & 140576.580 & 27.02 & 0.415 \\
\hline Rongjiruanjian & 0.000 & 0.000 & -1.639 & 62878.460 & 14.323 & 0.235 \\
\hline Jangfencicai & -0.001 & -1.415 & 0.000 & 41179.750 & 17.318 & 0.397 \\
\hline Yamadun & 0.000 & 0.000 & 0.000 & 0.000 & 0.000 & 0.000 \\
\hline Teruide & 0.000 & -0.841 & 0.000 & 17773.739 & 10.035 & 0.171 \\
\hline Tianlongguangqi & 0.000 & -0.627 & -1.944 & 102830.115 & 26.856 & 0.333 \\
\hline Huitianxincai & 0.000 & 0.000 & -0.329 & 79836.760 & 32.544 & 0.296 \\
\hline Shuzizhengtong & 0.000 & -0.339 & -1.752 & 71314.742 & 30.905 & 0.391 \\
\hline Yichengxinneng & 0.000 & 0.000 & 0.000 & 0.000 & 0.000 & 0.000 \\
\hline Dongfengrishen & -0.014 & -0.219 & 0.000 & 34793.913 & 32.657 & 0.114 \\
\hline Xianhehuanbao & 0.000 & -0.171 & -0.376 & 146073.198 & 32.315 & 0.378 \\
\hline Shenwuhuanbao & -0.092 & -1.447 & -4.079 & 91340.018 & 29.955 & 0.342 \\
\hline Zhendongzhiyao & 0.000 & -0.209 & 0.000 & 19294.955 & 6.474 & 0.27 \\
\hline Zhongdianhuanbao & 0.000 & 0.000 & -1.745 & 54193.470 & 29.156 & 0.339 \\
\hline Chulingxinxi & 0.000 & -0.140 & -0.471 & 76579.311 & 20.824 & 0.292 \\
\hline Tianhaohuanjing & 0.000 & -0.619 & 0.000 & 29829.158 & 10.399 & 0.259 \\
\hline Kanxinxincai & 0.000 & -0.168 & -1.645 & 90251.771 & 46.733 & 0.422 \\
\hline Shangqijituan & 0.000 & 0.000 & 0.000 & 0.000 & 0.000 & 0.000 \\
\hline Dongkuigufen & 0.000 & 0.000 & -0.654 & 78442.475 & 35.326 & 0.279 \\
\hline Zhongguoweixin & 0.000 & 0.086 & -1.398 & 34068.421 & 11.520 & 0.106 \\
\hline Mingjiangshuidian & -0.025 & -0.118 & 0.000 & 87325.61 & 39.403 & 0.931 \\
\hline Futianqiche & 0.000 & -0.315 & 0.000 & 48534.629 & 4.403 & 0.105 \\
\hline Yaxingkeche & 0.000 & 0.000 & 0.000 & 0.000 & 0.000 & 0.000 \\
\hline Hongduhangkong & 0.000 & 0.000 & 0.000 & 0.000 & 0.000 & 0.000 \\
\hline Zhenhuanzhonggong & 0.000 & 0.000 & 0.000 & 0.000 & 0.000 & 0.000 \\
\hline Hangtiandongli & 0.000 & -0.048 & -1.451 & 25464.296 & 22.394 & 0.304 \\
\hline Kunyaojituan & -0.032 & 0.000 & -1.519 & 30160.349 & 22.835 & 0.261 \\
\hline Hengtongguangdian & -0.105 & -0.162 & 0.000 & 26821.650 & 16.456 & 0.463 \\
\hline Guihanggufen & 0.000 & 0.000 & -1.182 & 17122.758 & 19.345 & 0.253 \\
\hline Yijinguangdian & -0.040 & 0.000 & 0.000 & 21774.204 & 23.125 & 0.436 \\
\hline Guangyuyuan & 0.000 & -1.102 & -3.212 & 65717.872 & 40.481 & 0.336 \\
\hline ShensangdaA & 0.000 & -0.018 & -0.232 & 25535.176 & 28.910 & 0.197 \\
\hline Xugongjixie & 0.000 & 0.000 & 0.000 & 0.000 & 0.000 & 0.000 \\
\hline Liugong & 0.000 & 0.000 & 0.000 & 0.000 & 0.000 & 0.000 \\
\hline Haimaqiche & 0.000 & 0.000 & 0.000 & 0.000 & 0.000 & 0.000 \\
\hline Qidiguhan & 0.000 & 0.000 & -4.174 & 14566.975 & 24.385 & 0.730 \\
\hline Shantuigufen & 0.000 & -0.168 & 0.000 & 26610.877 & 13.689 & 0.383 \\
\hline Xinyegufen & 0.000 & 0.000 & 0.000 & 69752.735 & 25.207 & 0.503 \\
\hline Xinhuazhiyao & 0.000 & -0.075 & 0.000 & 40120.632 & 16.200 & 0.265 \\
\hline Zhonghangfeiji & 0.000 & 0.000 & 0.000 & 12798.976 & 13.688 & 0.193 \\
\hline Qinchuangjichuang & 0.000 & -0.064 & 0.000 & 38789.499 & 8.516 & 0.184 \\
\hline Yingxingnengyuan & 0.000 & 0.000 & 0.000 & 0.000 & 0.000 & 0.000 \\
\hline Ankaiqiche & 0.000 & 0.000 & 0.000 & 0.000 & 0.000 & 0.000 \\
\hline Faershen & -0.117 & 0.000 & 0.000 & 25486.441 & 4.527 & 0.066 \\
\hline Yunneidongli & 0.000 & -0.280 & 0.000 & 24274.507 & 20.045 & 0.289 \\
\hline Shandahuate & 0.000 & -0.060 & -2.049 & 174714.085 & 51.620 & 0.444 \\
\hline Hebeixuangong & 0.000 & 0.000 & 0.000 & 0.000 & 0.000 & 0.000 \\
\hline Zhongguozhongqi & 0.000 & 0.000 & 0.000 & 0.000 & 0.000 & 0.000 \\
\hline Fuosukeji & -0.029 & 0.000 & 0.000 & 48994.168 & 26.473 & 0.414 \\
\hline
\end{tabular}




\begin{tabular}{|c|c|c|c|c|c|c|}
\hline Jiuzhitang & 0.000 & 0.000 & -1.248 & 166432.628 & 28.167 & 0.422 \\
\hline Shirongzhaoye & 0.000 & -0.328 & 0.000 & 107408.687 & 12.227 & 0.321 \\
\hline Zhouyankeji & 0.000 & -0.004 & 0.000 & 20462.589 & 18.245 & 0.152 \\
\hline Hengdiancidong & 0.000 & -0.026 & 0.000 & 68113.34 & 16.251 & 0.174 \\
\hline Zhonggangtianyuan & 0.000 & -0.041 & -2.975 & 19491.417 & 30.395 & 0.271 \\
\hline Suzhougude & 0.000 & -0.120 & -0.356 & 80698.624 & 29.726 & 0.273 \\
\hline Longjigufen & 0.000 & -0.688 & 0.000 & 64077.563 & 20.59 & 0.162 \\
\hline Zhongcaijieneng & -0.038 & -0.029 & 0.000 & 68721.151 & 32.05 & 1.086 \\
\hline Wowehecai & 0.000 & -0.072 & 0.000 & 53865.844 & 24.482 & 0.930 \\
\hline Yunhaijinshu & 0.000 & -0.042 & 0.000 & 56475.933 & 12.988 & 0.652 \\
\hline Zhengtongdianzi & 0.000 & -0.642 & 0.000 & 48599.723 & 20.119 & 0.911 \\
\hline Feimaguoji & 0.000 & -0.004 & 0.000 & 17575.694 & 4.236 & 0.071 \\
\hline Aotexun & 0.000 & 0.000 & 0.000 & 0.000 & 0.000 & 0.000 \\
\hline Aoweitongxin & 0.000 & -0.050 & 0.000 & 36361.104 & 31.237 & 0.380 \\
\hline Dahuagufen & -0.080 & -0.198 & -0.494 & 179403.522 & 47.499 & 0.853 \\
\hline Chuanrungufen & 0.000 & 0.000 & 0.000 & 0.000 & 0.000 & 0.000 \\
\hline Zhongdianxinlong & 0.000 & 0.000 & 0.000 & 70011.371 & 23.241 & 0.498 \\
\hline Dongfangyuanlin & 0.000 & -0.072 & 0.000 & 80761.497 & 43.21 & 0.612 \\
\hline Gelinmei & 0.000 & -0.196 & 0.000 & 12517.584 & 15.02 & 0.095 \\
\hline Longjijixie & 0.000 & 0.000 & 0.000 & 9272.367 & 8.299 & 0.055 \\
\hline Dongshanjimi & 0.000 & 0.000 & 0.000 & 0.000 & 0.000 & 0.000 \\
\hline Neimengyiji & 0.000 & -24.536 & -0.650 & 49365.468 & 33.769 & 0.668 \\
\hline Shenlutongxin & 0.000 & 0.000 & -1.074 & 149888.536 & 15.687 & 0.627 \\
\hline Haigetongxin & 0.000 & 0.000 & 0.000 & 0.000 & 0.000 & 0.000 \\
\hline Fuchunhuanbao & 0.000 & -0.094 & -0.566 & 74531.812 & 19.364 & 0.179 \\
\hline Keshida & 0.000 & 0.000 & -1.729 & 56778.582 & 8.519 & 0.219 \\
\hline Tianshunfenneng & 0.000 & 0.000 & 0.000 & 55440.784 & 13.472 & 0.216 \\
\hline Yataikeji & 0.000 & -0.064 & -0.140 & 134068.908 & 9.205 & 0.229 \\
\hline Yishenyaoye & 0.000 & 0.000 & 0.000 & 56894.906 & 8.25 & 0.221 \\
\hline Qinxinhuanjiang & -0.054 & -0.344 & -0.437 & 60688.857 & 17.181 & 0.225 \\
\hline Shenyanggufen & 0.000 & 0.000 & 0.000 & 85247.268 & 31.156 & 0.814 \\
\hline Daomingguangxue & 0.000 & 0.000 & 0.000 & 0.000 & 0.000 & 0.000 \\
\hline Maoshuodianyuan & 0.000 & 0.000 & 0.000 & 30861.118 & 17.04 & 0.317 \\
\hline Jingweigufen & 0.000 & 0.000 & 0.000 & 59379.072 & 16.477 & 0.182 \\
\hline Teyiyaoye & 0.000 & -0.033 & 0.000 & 99377.684 & 41.433 & 1.367 \\
\hline Ankeshenwu & 0.000 & -0.074 & -3.422 & 174345.975 & 36.644 & 1.380 \\
\hline Jiqiren & 0.000 & -0.040 & -2.907 & 75787.729 & 33.255 & 0.313 \\
\hline Meitainuo & 0.000 & 0.000 & 0.000 & 0.000 & 0.000 & 0.000 \\
\hline Hekanxinneng & 0.000 & 0.000 & 0.000 & 66829.264 & 15.045 & 0.134 \\
\hline Yujingongshi & 0.000 & -0.214 & 0.000 & 85871.670 & 23.578 & 0.251 \\
\hline Nandudianyuan & 0.000 & 0.000 & 0.000 & 0.000 & 0.000 & 0.000 \\
\hline Danshengkeji & 0.000 & -0.208 & -3.000 & 54205.159 & 22.379 & 0.314 \\
\hline Shwnyunhuanbao & 0.000 & -0.238 & 0.000 & 44542.284 & 7.848 & 0.414 \\
\hline Jiayugufen & 0.000 & 0.000 & 0.000 & 12784.866 & 7.483 & 0.119 \\
\hline Zhenjiangdingli & -1.172 & -0.373 & -0.084 & 236065.005 & 15.439 & 0.976 \\
\hline Dafukeji & 0.000 & 0.000 & 0.000 & 0.000 & 0.000 & 0.000 \\
\hline Weiminghuanbao & -0.166 & -0.053 & -2.165 & 262063.597 & 15.355 & 0.382 \\
\hline Yongqinghuanbao & 0.000 & -0.210 & 0.000 & 7383.245 & 3.324 & 0.023 \\
\hline Xinwangda & -0.062 & -0.249 & 0.000 & 103385.651 & 58.161 & 0.898 \\
\hline Qianshanyaoji & -0.081 & -0.775 & 0.000 & 94193.722 & 49.249 & 1.331 \\
\hline Dongfangdianre & -0.016 & 0.000 & -0.132 & 11896.317 & 2.508 & 0.26 \\
\hline Meichengkeji & 0.000 & -0.054 & 0.000 & 124891.553 & 39.099 & 0.936 \\
\hline Dianzhenduan & 0.000 & -0.196 & 0.000 & 69150.546 & 25.324 & 1.419 \\
\hline Chanshangyaoye & 0.000 & -0.094 & 0.000 & 148625.157 & 26.766 & 0.547 \\
\hline Jingduankeji & 0.000 & -0.061 & 0.000 & 50181.755 & 16.143 & 0.194 \\
\hline Baanshuiwu & -0.002 & -0.315 & 0.000 & 64279.519 & 25.043 & 1.076 \\
\hline Hejiagufen & 0.000 & -0.037 & -0.209 & 158250.221 & 12.974 & 0.733 \\
\hline Yangguangdianyuan & 0.000 & -0.235 & 0.000 & 74286.702 & 43.072 & 0.280 \\
\hline Sannuoshenwu & 0.000 & -0.104 & -2.207 & 74177.356 & 35.311 & 0.327 \\
\hline Zhongjizhuangbei & 0.000 & 0.000 & -3.098 & 6087.037 & 9.408 & 0.316 \\
\hline Bohuichuangxin & 0.000 & -0.014 & -2.457 & 55965.323 & 31.041 & 0.307 \\
\hline
\end{tabular}




\begin{tabular}{|c|c|c|c|c|c|c|}
\hline Jinmokeji & 0.000 & -0.042 & -0.410 & 54844.500 & 28.548 & 0.477 \\
\hline Mengcaoshentai & -0.046 & -0.538 & 0.000 & 63979.381 & 30.813 & 0.865 \\
\hline Xuelanghuanjing & -0.064 & -0.237 & 0.000 & 68828.163 & 34.214 & 1.303 \\
\hline Zhonglaigufen & -0.147 & -0.820 & 0.000 & 79324.005 & 34.657 & 1.616 \\
\hline Feilihua & 0.000 & -0.026 & -1.388 & 167210.279 & 43.454 & 1.319 \\
\hline Huannengkeji & 0.000 & -0.255 & -1.322 & 177441.023 & 9.057 & 0.678 \\
\hline Sitongxincai & -0.037 & -0.165 & -3.776 & 245600.101 & 6.8191 & 1.224 \\
\hline Shanheyaopu & -0.039 & -0.028 & -2.090 & 185319.158 & 23.659 & 2.674 \\
\hline Maikeshenwu & -0.058 & -0.039 & -2.939 & 211521.844 & 12.638 & 0.186 \\
\hline Zhongfeigufen & 0.000 & 0.000 & -1.265 & 102966.756 & 42.886 & 1.703 \\
\hline Meishangshentai & 0.000 & -0.095 & -0.041 & 174085.933 & 17.910 & 1.162 \\
\hline Gaolaigufen & -0.013 & -0.215 & 0.000 & 103455.664 & 47.244 & 2.263 \\
\hline Wandongyiliao & 0.000 & 0.000 & 0.000 & 0.000 & 0.000 & 0.000 \\
\hline Huanrunshuanghe & -0.052 & 0.000 & 0.000 & 4082.097 & 5.206 & 0.232 \\
\hline Yutongkeche & -0.173 & 0.000 & 0.000 & 38082.141 & 31.219 & 0.697 \\
\hline Jinhuangufen & 0.000 & -0.158 & -0.759 & 43213.663 & 37.999 & 0.546 \\
\hline Yongdinggufen & 0.000 & 0.000 & -0.564 & 24992.859 & 26.809 & 0.257 \\
\hline Beifangxitu & 0.000 & 0.000 & -2.125 & 29832.154 & 26.138 & 0.347 \\
\hline Juhuagufen & 0.000 & 0.000 & 0.000 & 0.000 & 0.000 & 0.000 \\
\hline Jangsuwuzhong & 0.000 & 0.000 & -0.694 & 52472.874 & 35.635 & 0.402 \\
\hline Guangshengyouse & 0.000 & -2.244 & -1.830 & 14884.346 & 18.645 & 0.190 \\
\hline Haizhengyaoye & 0.000 & 0.000 & 0.000 & 0.000 & 0.000 & 0.000 \\
\hline Guodiannanzi & 0.000 & -0.007 & 0.000 & 17710.411 & 1.739 & 0.026 \\
\hline Hengruiyiyao & -0.039 & -0.081 & -7.149 & 161540 & 49.987 & 0.515 \\
\hline Taihuagufen & 0.000 & -0.082 & 0.000 & 21253.228 & 16.573 & 0.265 \\
\hline Shiyinggufen & 0.000 & -0.030 & -0.745 & 246135.436 & 21.039 & 0.362 \\
\hline Hangfakeji & 0.000 & -0.007 & -0.354 & 13096.106 & 19.235 & 0.326 \\
\hline Hanlanhuanjing & 0.000 & -0.052 & 0.000 & 43345.526 & 18.634 & 0.461 \\
\hline Changjiangtongxin & 0.000 & -0.238 & 0.000 & 31172.164 & 25.166 & 0.345 \\
\hline Lianchuangguangdain & 0.000 & -0.049 & -1.045 & 70237.035 & 39.413 & 0.409 \\
\hline Ningboshenrun & 0.000 & -0.260 & -0.113 & 120932.102 & 37.786 & 0.329 \\
\hline Shandongjintai & 0.000 & 0.000 & 0.000 & 0.000 & 0.000 & 0.000 \\
\hline Wukuangziben & 0.000 & 0.000 & -0.746 & 32315.936 & 15.479 & 0.397 \\
\hline Sanyouhuangong & 0.000 & -0.359 & 0.000 & 12707.922 & 8.807 & 0.105 \\
\hline Jianghuaiqiche & -0.028 & -0.085 & 0.000 & 18642.877 & 28.835 & 0.142 \\
\hline Peilingdianli & -0.011 & -0.208 & -0.679 & 172145.014 & 19.389 & 0.286 \\
\hline Baotaigufen & 0.000 & 0.000 & 0.000 & 0.000 & 0.000 & 0.000 \\
\hline Guiyanboye & 0.000 & -0.066 & -0.783 & 12054.693 & 18.284 & 0.195 \\
\hline Laobaixing & 0.000 & -0.087 & 0.000 & 95447.183 & 13.253 & 0.475 \\
\hline Fenghuotongxin & 0.000 & 0.000 & 0.000 & 0.000 & 0.000 & 0.000 \\
\hline Zhongtiankeji & 0.000 & -0.110 & 0.000 & 74593.280 & 34.379 & 0.699 \\
\hline Changyuanjituan & 0.000 & -0.009 & 0.000 & 18489.78 & 17.813 & 0.570 \\
\hline Feidahuanbao & 0.000 & -0.095 & 0.000 & 20890.466 & 5.011 & 0.183 \\
\hline Xiamengwuye & 0.000 & -0.446 & 0.000 & 29729.828 & 23.207 & 0.435 \\
\hline Tiandikeji & 0.000 & -0.147 & 0.000 & 4684.167 & 5.628 & 0.114 \\
\hline Nanjingxiongmao & 0.000 & -1.022 & 0.000 & 22244.929 & 30.184 & 0.307 \\
\hline Shangchaigufen & 0.000 & -0.093 & 0.000 & 26059.281 & 9.054 & 0.081 \\
\hline Hangfadongli & 0.000 & 0.000 & 0.000 & 0.000 & 0.000 & 0.000 \\
\hline Bohaihuosai & 0.000 & -0.023 & -0.202 & 40463.024 & 21.251 & 0.309 \\
\hline
\end{tabular}

